\title{
Retrieval and validation of ozone columns derived from measurements of SCIAMACHY on Envisat
}

H. J. Eskes ${ }^{1}$, R. J. van der A ${ }^{1}$, E. J. Brinksma ${ }^{1}$, J. P. Veefkind ${ }^{1}$, J. F. de Haan ${ }^{1}$, and P. J. M. Valks ${ }^{2}$

${ }^{1}$ Royal Netherlands Meteorological Institute, De Bilt, The Netherlands

${ }^{2}$ German Aerospace Center, Oberpfaffenhofen, Germany

Received: 29 March 2005 - Accepted: 20 May 2005 - Published: 4 July 2005

Correspondence to: H. J. Eskes (eskes@knmi.nl)

(C) 2005 Author(s). This work is licensed under a Creative Commons License.

\section{$5,4429-4475,2005$}

\section{Retrieval and validation of SCIAMACHY ozone columns}

H. J. Eskes et al.

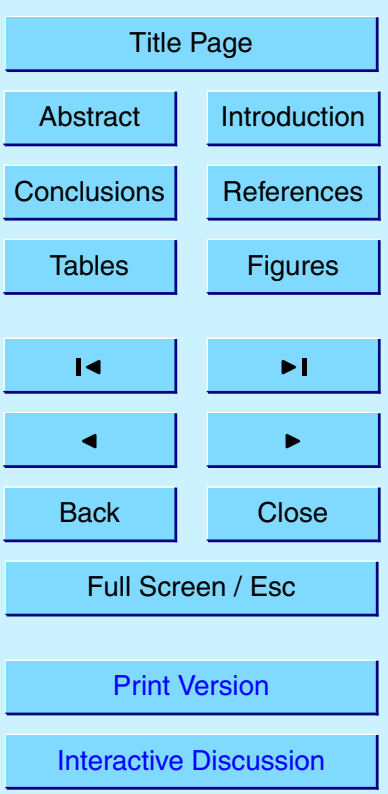




\section{Abstract}

This paper describes a new ozone column retrieval algorithm and its application to SCIAMACHY measurements. The TOSOMI algorithm is based on the Differential Optical Absorption Spectroscopy (DOAS) technique and implements several improvements 5 over older algorithms. These improvements include aspects like (i) the explicit treatment of rotational Raman scattering, (ii) an improved air-mass factor formulation which is based on a simulation of the reflectivity spectrum and a subsequent DOAS fit of this simulated spectrum, (iii) the use of an improved ozone climatology and a column dependent air-mass factor, (iv) the use of daily varying ECMWF temperature profile anal10 yses. The results of three validation exercises are reported. The TOSOMI columns are compared with an extensive set of ground-based observations (Brewer, Dobson) for the years 2003 and 2004. Secondly, a direct comparison for January-June 2003 with two new GOME retrievals, GDP Version 4 and TOGOMI, is presented. Third, data assimilation is used to study the dependence of the TOSOMI columns with retrieval parameters such as the viewing angle, cloud fraction and geographical location. These comparisons show a good consistency on the percent level between the GOME and SCIAMACHY algorithms. The present TOSOMI implementation (v0.32) shows an offset of about $-1.5 \%$ with respect to ground-based observations and the GOME retrievals.

\section{Introduction}

Total column ozone measurements from satellites have been important in documenting day to day and long-term changes in ozone. Especially the Total Ozone Mapping Spectrometer (TOMS) instruments, e.g. Bhartia and Wellemeyer (2004) and the Solar Backscatter UltraViolet (SBUV) instruments (Bhartia et al., 1996) have played a crucial role in monitoring the ozone distribution since 1979 and the changes in the Antarctic and Arctic ozone hole in particular (WMO, 2003). A European contribution to this
ACPD

$5,4429-4475,2005$

\section{Retrieval and validation of \\ SCIAMACHY ozone columns}

H. J. Eskes et al.

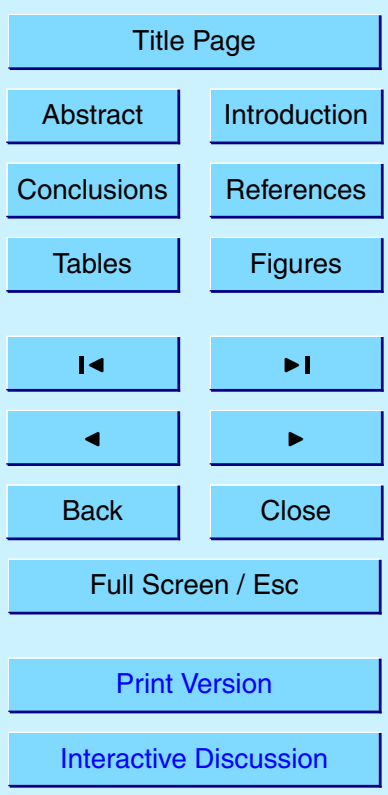

EGU 
long-term ozone column monitoring consists of Global Ozone Monitoring Instrument (GOME) on ERS-2 (Burrows et al., 1999a), SCIAMACHY on Envisat (Bovensmann et al., 1999) and OMI on EOS-AURA (Veefkind et al., 2002). Apart from the long-term record and coverage it is in particular the perceived high accuracy (on the few percent 5 level) of these UV-VIS instruments which contributes to their popularity. An important trend-monitoring requirement for the ozone data sets is the long-term stability which should be on the order of $1 \%$ to be able to document changes in the ozone layer and the possible recovery resulting from the reduction of ozone depleting substances.

However, the development of high-quality retrieval algorithms is non-trivial and re10 quires detailed instrument knowledge and a careful description of atmospheric processes. During 2004 a new version of the TOMS algorithm, Version 8, has become available (Bhartia and Wellemeyer, 2004). Similarly, a new reprocessing has become available for GOME, GOME Data Processor (GDP) Version 4 (Spurr et al., 2004). Both new algorithms implement substantial improvements over older TOMS and GOME processor versions. The GDP-4 is based on the GDOAS algorithm developed at BIRAIASB. GDOAS was one of three new DOAS-type algorithms developed for GOME in response to an ESA Invitation to Tender. The other two algorithms are the weighting function DOAS developed by the University of Bremen (Coldewey-Egbers et al., 2004; Weber et al., 2004) and the TOGOMI algorithm developed by KNMI (Valks and van Oss, 2003). All three algorithms were shown to improve considerably upon GOME GDP Version 3.

The present operational ESA algorithm for SCIAMACHY is based on the older GDP Version 2.7 of GOME. Known problems with this algorithm were an important motivation for us to develop our own SCIAMACHY total ozone retrieval algorithm. A second important motivation for an independent implementation is the verification and validation of the official ESA ozone column products. Our algorithm is called "Total Ozone retrieval scheme for SCIAMACHY based on the OMI DOAS algorithm" (TOSOMI). It is based on the TOGOMI retrieval algorithm, and has been coupled to the SCIAMACHY level-1 measurements with only minor modifications to the code. The
ACPD

$5,4429-4475,2005$

\section{Retrieval and validation of \\ SCIAMACHY ozone columns}

H. J. Eskes et al.

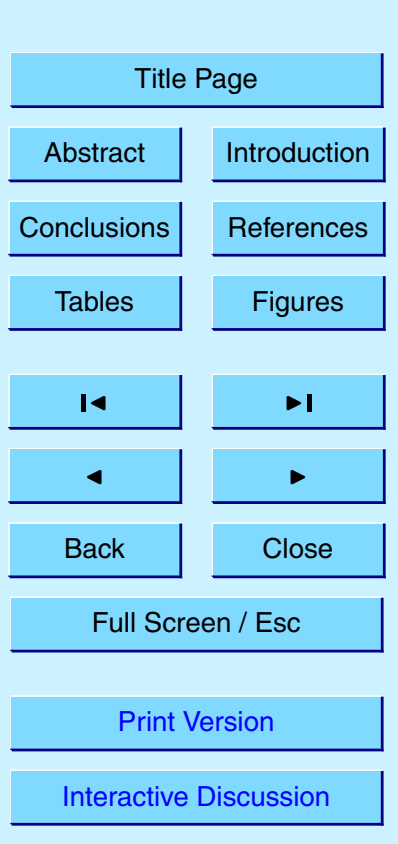


TOSOMI algorithm is currently applied operationally: as soon as a new level-1 data file from SCIAMACHY becomes available this is processed with TOSOMI and the retrieved columns are made available via internet, http://www.temis.nl/. TOSOMI is a fast algorithm, and processing of one orbit of SCIAMACHY on average takes $88 \mathrm{~s}$ on a $500 \mathrm{MHz}$

5 R14000 SGI/MIPS processor. Applications of the near-real time ozone product are the ozone data assimilation and forecasting at KNMI (Eskes et al., 2003), and surface ultraviolet calculations (UV index and dose). The TOSOMI product is currently also used by ECMWF in their operational assimilation (Dethof and Hólm, 2004).

In the next section we will provide an overview of the DOAS implementation of 10 TOSOMI. The validation of the TOSOMI ozone column values with ground-based Brewer and Dobson measurements is presented in Sect. 3. Direct comparisons with GOME retrievals are discussed in Sect. 4. Finally, in Sect. 5 data assimilation is used to study the dependence of the retrieval on parameters such as the SCIAMACHY instrument viewing angle.

\section{The TOSOMI retrieval scheme}

The total ozone retrieval algorithm TOSOMI (currently Version 0.32, November 2003) is an application of the TOGOMI algorithm to SCIAMACHY. The recently developed GOME algorithm TOGOMI (Valks and van Oss, 2003) is itself based on the total ozone DOAS (Differential Optical Absorption Spectroscopy) algorithm developed for the OMI 20 instrument (Veefkind et al., 2002, 2005). The OMI, SCIAMACHY and GOME instruments are similar spectrometers measuring the backscattered solar radiation in the UV and visible. Relatively minor adaptations are needed to apply the DOAS total ozone column retrieval to the other instruments. The SCIAMACHY total ozone retrieval algorithm TOSOMI combines a reading module for SCIAMACHY level-1 data with the 25 TOGOMI DOAS modules. The FRESCO algorithm (Koelemeijer et al., 2001) is applied to the SCIAMACHY spectra to obtain cloud fraction and cloud-top pressure estimates. The main improvements of the new algorithm as compared to existing DOAS algo-

ACPD

$5,4429-4475,2005$

\section{Retrieval and validation of \\ SCIAMACHY Ozone columns}

H. J. Eskes et al.

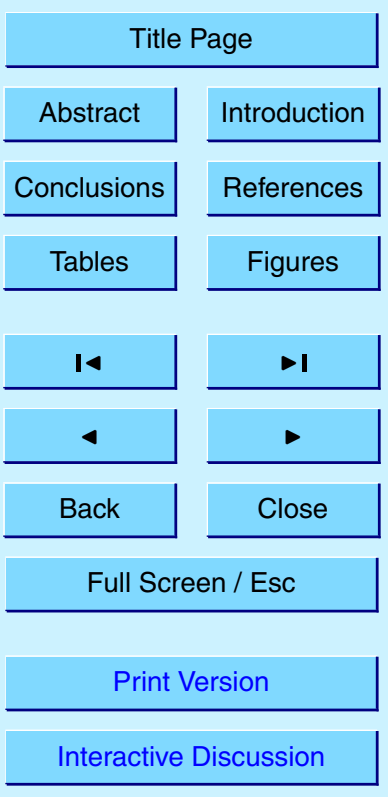

EGU 
rithms of a few years ago are:

(i) a new treatment of Raman scattering in DOAS (De Haan, 2003). This new formulation of DOAS explicitly accounts for the Raman smoothing of the solar Fraunhofer lines as well as the ozone absorption structures,

5 (ii) improvements in the calculation of the air mass factor, using the so-called empirical approach (Marquard et al., 2000; Veefkind et al., 2002),

(iii) the use of an improved column-dependent ozone climatology (also used for the TOMS v8 algorithm (Bhartia and Wellemeyer, 2004)),

\section{Retrieval and validation of \\ SCIAMACHY ozone columns}

H. J. Eskes et al.

(iv) the use of air-mass factors that depend on the ozone column,

(v) use of the Fast Retrieval Scheme for Clouds from the Oxygen A-band (FRESCO) algorithm for cloud corrections, (vi) the treatment of the atmospheric temperature sensitivity by using effective ozone cross-sections calculated from ECMWF temperature profiles, and (vii) the use of a semi-spherical polarization-dependent radiative transfer model (KNMI DAK) (De Haan, 1987).

\subsection{Differential Optical Absorption Spectroscopy}

The Differential Optical Absorption Spectroscopy retrieval approach is distinguished from other retrieval approaches on two aspects: (i) The trace gas information is obtained from differential features that vary rapidly with wavelength. The smooth wavelength dependence dominated by Rayleigh scattering or surface albedo variations are removed by introducing a low-order polynomial, acting as a high-pass filter. (ii) DOAS is usually defined as a two-step process. The reflectance spectrum observed is compared with a set of cross sections of species absorbing in a chosen wavelength window. In more elaborate formulations these cross sections may be replaced by effective cross sections or weighting functions (Coldewey-Egbers et al., 2004). The amplitude of the spectral features is a measure of the tracer amount along the light path, called the slant

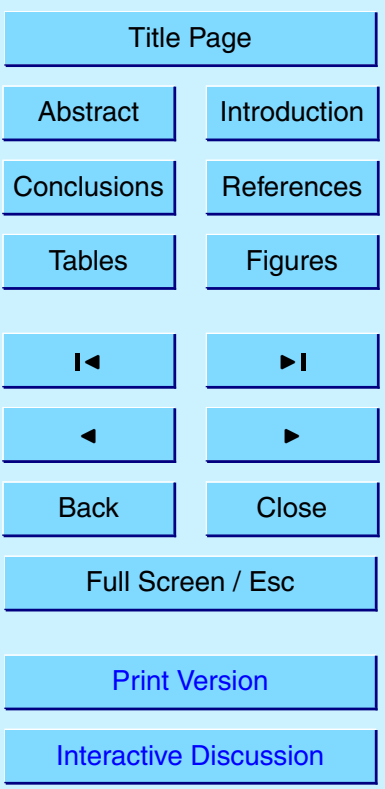


column. In the second step the slant column is related to a vertical tracer column by dividing it by an air-mass factor (AMF) computed with a radiative transfer model. This AMF is a single number and the resulting retrieval scheme is fast due to the compact radiative transfer (AMF) look-up tables.

5 In its simplest form (for one particular light path and for monochromatic light) we can write the top-of-the-atmosphere reflectance $\pi l / F_{0}$ as,

$\frac{\pi /(\lambda)}{F_{0}(\lambda)}=P(\lambda) e^{-N \sigma_{O 3}(\lambda)}$

where, $\lambda$ is the wavelength, $I$ is the earth radiance, $F_{0}(\lambda)$ is the extraterrestrial solar irradiance, $\sigma_{O_{3}}(\lambda)$ is the ozone absorption cross section, and $P(\lambda)$ is a low order 10 polynomial as a function of wavelength. This equation has the same form as the wellknown Lambert-Beer law. $N$ is the so-called slant column density, the amount of ozone integrated along the path of the light. It is determined by comparing the absorption features appearing in the reflectance (or logarithm of the reflectance) with reference cross sections of the species of interest. This is done on a predefined window with strong differential ozone features, where the effects of other absorbers and/or instrument artefacts are small or well characterised.

In reality the reflectivity is a weighted sum over wavelengths and over all possible paths the light can travel, originating from the sun, scattering in the atmosphere or at the surface and entering the satellite instrument at the correct angle. The polynomial, the slant column and the (temperature of the) cross section all depend on the light path, and a full radiative transfer calculation is needed to relate observed absorption features to vertical columns of $\mathrm{O}_{3}$.

\subsection{Rotational Raman}

One of the assumptions underlying Eq. (1) is that scattering on air molecules is elas-

tic. In reality about $4 \%$ of all scattering events on air molecules is inelastic - due to rotational Raman scattering - resulting in a shift in the photon wavelength up to

ACPD

5, 4429-4475, 2005

\section{Retrieval and validation of \\ SCIAMACHY ozone columns}

H. J. Eskes et al.

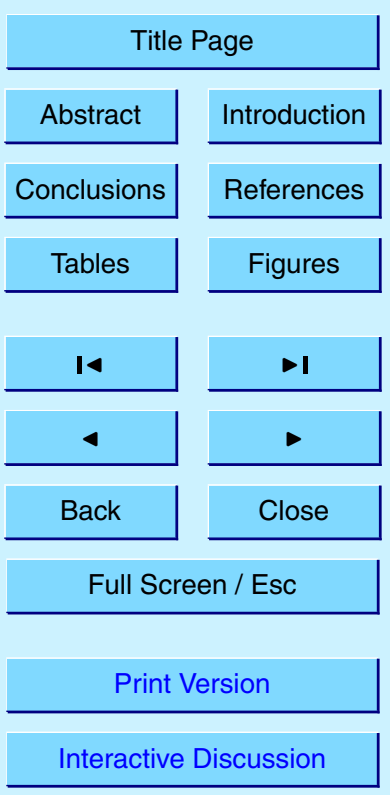

EGU 
$2 \mathrm{~nm}$ (Chance and Spurr, 1997; Vountas et at., 1998). As a consequence the solar Fraunhofer spectral lines are smoothed when the light is scattered by molecules in the atmosphere. The atmospheric absorption structures observed by the satellite are influenced as well, resulting in more-shallow line depths. This has an immediate effect 5 on DOAS trace gas retrievals: a neglect of Raman scattering results in ozone columns that are too small. This error is in the range of $3 \%$ to $10 \%-$ depending on the geometry - and a proper treatment of this effect is clearly required (Van Roozendael et al., 2002; De Haan, 2003; Coldewey-Egbers et al., 2004).

We follow the approach introduced by De Haan (2003) to deal with Raman scattering 10 in the ozone column retrieval. Equation (1) is adjusted to account for Raman scattering by writing the observed reflectivity as a sum of terms corresponding to elastic and inelastic scattered radiation:

$\frac{I(\lambda)}{F_{0}(\lambda)}=P_{e /}(\lambda) e^{-\sigma_{O 3}^{e l}(\lambda) N_{e l}}+P_{\text {inel }}(\lambda) \frac{I_{\text {Ring }}^{e f f}(\lambda)}{F_{0}(\lambda)} \exp \left[-N_{n s} \sigma_{O 3}^{n s}(\lambda)-N_{s} \sigma_{O 3}^{s}(\lambda)\right]$.

Here, $P_{e l}$ and $P_{\text {inel }}$ are low degree polynomials in the wavelength, representing the 15 overall wavelength dependence due to elastic and inelastic scattering. $\sigma_{O 3}^{e l}, \sigma_{O 3}^{n s}$, and $\sigma_{O 3}^{S}$ are effective absorption cross section for elastic scattering, for the scrambled and non-scrambled parts of the optical path. $N_{e l}, N_{n s}$ and $N_{s}$ are the slant columns for elastic scattering and for the non-scrambled and scrambled parts of the inelastic scattering light paths, after and before the Raman scattering event respectively. $l_{\text {Ring }}^{\text {eff }}$ is the so-called Ring spectrum due to the scrambling of Fraunhofer lines in the solar irradiance. A detailed derivation of Eq. (2) and definitions of the cross sections can be found in De Haan (2003).

The interpretation of Eq. (2) is given in Fig. 1. Just before entering the atmosphere the sun-normalised radiance is a constant by definition (top panel). On it's path from 25 the sun into the atmosphere, the light experiences ozone absorption and the intensity shows the characteristic ozone cross-section features (second panel). In the case of inelastic scattering the spectrum is scrambled and a large part of the ozone absorption

ACPD

$5,4429-4475,2005$

\section{Retrieval and validation of SCIAMACHY ozone columns}

H. J. Eskes et al.

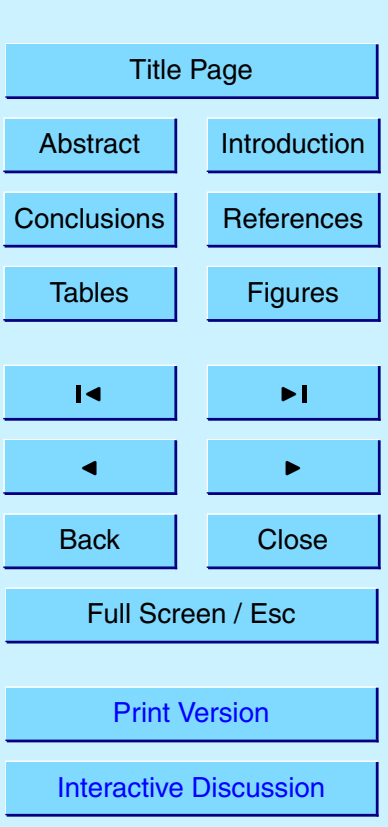

EGU 
features have disappeared due to the smoothing, as described by $\sigma_{O 3}^{s}$ (third panel on the right). On the path to the satellite sensor ozone absorption features are picked up again like in the case of elastic scattering (fourth panel). The inelastic broadening of the solar Fraunhofer spectral features causes the characteristic Ring features to appear 5 in the sun normalised radiance.

The Ring spectra and ozone cross section are easily distinguished and are fitted separately. The Ring spectrum amplitude derived from the spectral fitting represents a direct measurement of the amount of Raman scattering. Equation (2) has been derived with two simplifying assumptions: (i) the absorber is situated completely above the scattering layer, and (ii), observed radiation is scattered only once (elastic or inelastic). In the TOSOMI implementation we approximate the non-scrambled and scrambled slant paths as $N_{n s}=N_{e l} w /\left(w+w_{0}\right)$ and $N_{s}=N_{e /} w_{0} /\left(w+w_{0}\right)$, with $w_{0}=1 / \cos \theta_{0}$ and $w=1 / \cos \theta$. The $\theta_{0}$ and $\theta$ are the zenith angles for the sun and satellite viewing directions, and $N_{e l}$ is the slant ozone column for elastic scattering.

15 2.3. Air mass factor

By definition the air-mass factor is defined as the ratio between the slant and the vertical ozone column. Normally this air-mass factor is calculated with a radiative transfer model as $\partial \ln I /\left(\partial N_{v} \sigma\right)$ or $\left[\ln /\left(N_{v}\right)-\ln /(0)\right] /\left[N_{v} \sigma\right]$, motivated by Eq. (1). Here $N_{v}$ is the vertical ozone column. However, the air-mass factor determined in this way will result in several errors of the order of a percent of more, mainly related to aspects like the choice of wavelength for the AMF calculation and non-linearities (ozone is not a weak absorber in the chosen wavelength window). The empirical AMF approach (Marquard et al., 2000; Veefkind et al., 2002, 2005) reproduces the entire DOAS procedure (see Fig. 2): DOAS slant-column estimates performed on a modelled reflectivity spectrum are compared with DOAS slant-column estimates derived from SCIAMACHY measurements. The AMF represents the weighted sum of the different photon paths within the fit window. Because the DOAS fitting step is identical in both cases, DOAS specific errors like the ones mentioned above will tend to cancel out.

ACPD

$5,4429-4475,2005$

\section{Retrieval and validation of \\ SCIAMACHY ozone columns}

H. J. Eskes et al.

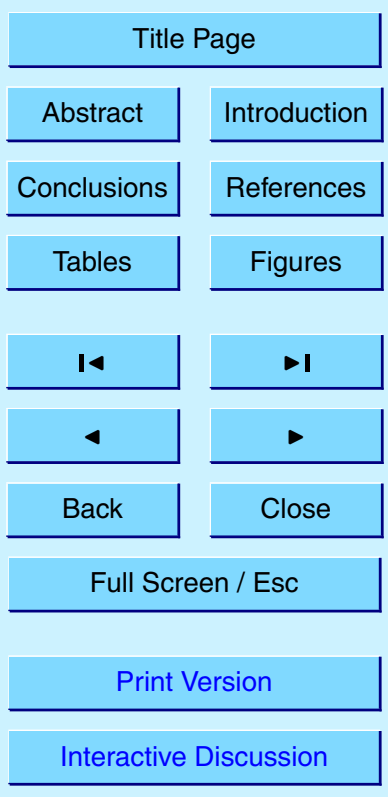

EGU 
The radiative transfer model used for the simulations of spectra is the DoublingAdding-KNMI (DAK) model (De Haan, 1987). This model accounts for the polarisation of light and (quasi) spherical geometry at high solar zenith angles. The AMF calculations are based on a set of ozone profiles that cover the natural variability of the ozone 5 profile for a given location and time period. For each of these profiles the AMF is calculated for a given sun/satellite geometry and surface properties. Profiles are taken from the ozone profile climatology from Logan, Labow \& McPeters, which is also used in the TOMS V8 total ozone algorithm (Bhartia and Wellemeyer, 2004). This climatology contains 3 (at low-latitudes) to 10 (at high-latitudes) column classified ozone profiles per 1010 latitude band for each month. In this way the effective AMF is a function of the slant column determined in the DOAS fit, and is determined by interpolating between the relevant climatological profiles. The surface reflectivity is determined from a monthly climatology based on TOMS observations (Herman and Celarier, 1997).

The algorithm uses a pre-calculated look-up-table of AMFs, which results in a fast 15 algorithm ideally suited for near-real time applications. The AMF is a function of the sun and satellite geometry, the surface pressure and albedo, the latitude and month, and the ozone slant column. The air-mass factors are normalised by a simple geometrical AMF which reduces interpolation errors.

\subsection{Clouds}

20 The cloud fraction and cloud pressure are derived from the SCIAMACHY observations with the Fast Retrieval Scheme for Clouds from the Oxygen A-band (FRESCO) method (Koelemeijer et al., 2001; Fournier et al., 2004). The FRESCO code is integrated within the TOSOMI algorithm and the cloud retrieval precedes the DOAS ozone column retrieval. The cloud fraction is derived assuming the cloud behaves like a Lambertian

reflector with albedo 0.8 , corresponding to an optically thick cloud. FRESCO assumes that the pixel can be divided in a cloud-free part and an optically thick cloudy part. Therefore both cloud pressure and cloud fraction should be interpreted as effective optical properties of the atmosphere in the presence of clouds.
ACPD

$5,4429-4475,2005$

\section{Retrieval and validation of \\ SCIAMACHY ozone columns}

H. J. Eskes et al.

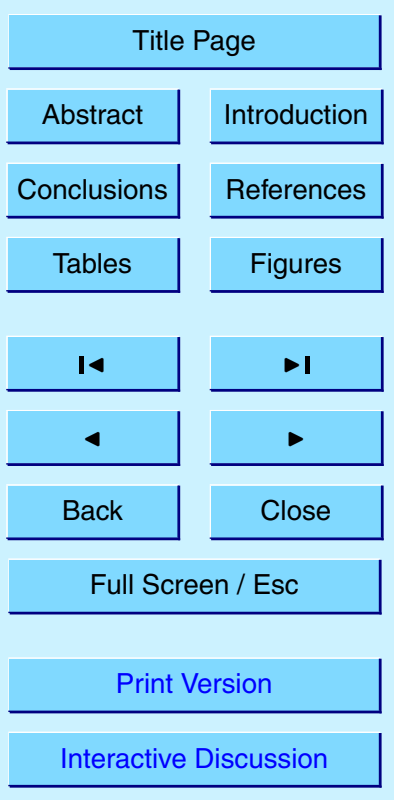

EGU 
The air-mass factor $M$ in the retrieval depends on the cloud fraction through the following equation,

$M=w M_{\text {cloudy }}+(1-w) M_{\text {clear }}$

where $w$ is the fraction of the radiance originating from the cloudy part of the atmo-

5 sphere. These fractions are pre-computed with the DAK model and are stored in a separate look-up table. The cloudy AMF depends on the cloud pressure, modelled as a "surface" with albedo 0.8 , located in practice somewhere inside the cloud. Finally, a vertical column is computed by adding a "ghost column" $N_{g}$, derived from the ozone profile climatology,

$$
{ }_{10} N_{v}=\frac{N_{s}+w M_{\text {cloudy }} N_{g}}{M} \text {. }
$$

The ghost column accounts for the column between the surface and the cloud pressure level which can not be observed by the satellite.

\subsection{Cross sections}

Two wavelength windows have been considered for the ozone retrieval. These are 15 the traditional GOME $325-335 \mathrm{~nm}$ window and a $5 \mathrm{~nm}$ wide window centred around $334.1 \mathrm{~nm}$ (Veefkind et al., 2002). The first has the advantage of a better signal to noise ratio. The latter has the advantage of a near temperature independence and a somewhat improved sensitivity in the lower troposphere. For the SCIAMACHY implementation we use the $325-335 \mathrm{~nm}$ window which was also chosen in the implementation for 20 GOME (Valks and van Oss, 2003). A main motivation for following these settings is that it allows a direct comparison between SCIAMACHY and the GOME-TOGOMI retrieval which uses the same wavelength window.

Different ozone absorption cross-sections are available, and three sets have been implemented in TOSOMI: the GOME Flight Model (GFM) (Burrows et al., 1999b), the SCIAMACHY Flight Model (SFM) (Bogumil et al., 2003) and Bass and Paur (B\&P)

ACPD

5, 4429-4475, 2005

\section{Retrieval and validation of \\ SCIAMACHY ozone columns}

H. J. Eskes et al.

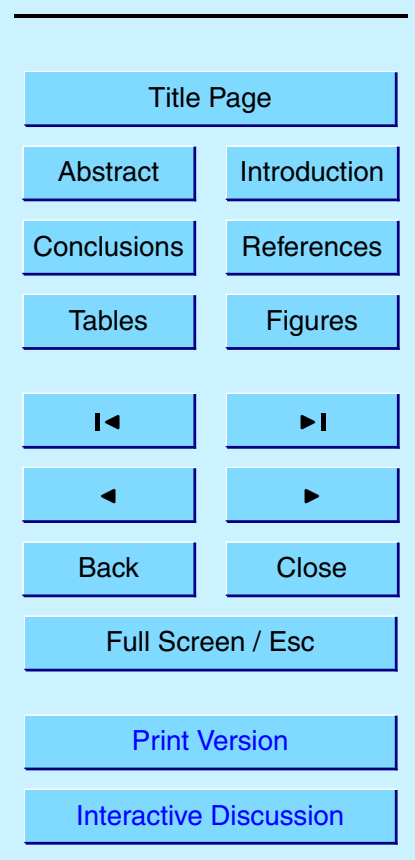

EGU 
cross-sections (Bass and Paur, 1986). The GFM and SFM cross-sections have been measured at 5 different temperatures during the pre-flight calibration of the spectrometers. The B\&P cross-sections have been measured at high resolution (better than $0.025 \mathrm{~nm}$ ) and have been recommended as a standard for use in remote-sensing ap5 plications (Orphal, 2002).

Following the implementation for GOME (Valks and van Oss, 2003), we apply an additional broadening of $0.45 \mathrm{~nm}$ to the cross sections as well as to the measured spectra. In this way the retrieval becomes less sensitive to spectral calibration errors and to slit function specification errors, and artefacts related to under-sampling by the 10 spectrometer are reduced. The characteristic ozone features with $2-3 \mathrm{~nm}$ wide peaks remain preserved in the fitting window. The study of the accuracy of GDP Version 3 total ozone product by Van Roozendael et al. (2002) shows the importance of the crosssection quality and the treatment of the temperature dependence in the DOAS fit. This study indicates that the use of GFM cross-sections results in a high quality and stable DOAS fit when applying a fixed shift of $+0.017 \mathrm{~nm}$ to the cross-sections. This shift was applied to the GFM cross sections.

From comparisons like the one shown in Fig. 3 we conclude that: i) The shape of the three absorption cross sections agrees well. All three produce satisfactory small DOAS fit uncertainties on average of the order of $0.6 \%$. An example of a fit based on the GFM is shown in Fig. 4. ii) The peak-valley amplitude is significantly different: B\&P is about $4 \%$ smaller than GFM, SFM about $8 \%$ smaller than GFM. With the B\&P cross sections the retrieved columns are found to be about $2 \%$ higher than ground-based observations. The SFM cross sections result in retrieved values that are about $5 \%$ higher than ground-based observations. The broadened GFM cross-sections are used for the baseline processing of TOSOMI. With this choice the TOSOMI retrievals are about $1.5 \%$ low compared to Brewer and Dobson observations, as discussed in the next section.

To account for the temperature dependence, an effective ozone absorption temperature is calculated using daily temperature analyses $T^{e c}$ from the European Centre for
ACPD

$5,4429-4475,2005$

\section{Retrieval and validation of \\ SCIAMACHY ozone columns}

H. J. Eskes et al.

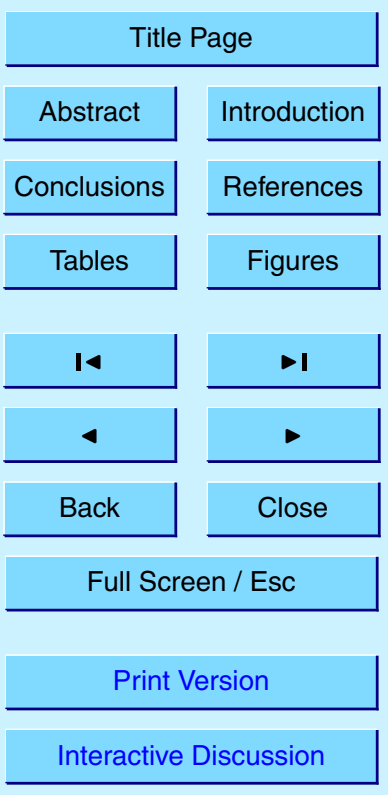

EGU 
Medium-Range Weather Forecasts (ECMWF) model. This effective temperature $T^{\text {eff }}$ is equal to the temperature $T$ that minimises the following equation,

$\int d \lambda\left\{\sigma_{O 3}(T, \lambda)-\int d z \rho(z) \sigma_{O 3}\left(T^{e c}(z), \lambda\right)\right\}^{2}$

where $\rho(z)$ is a climatological ozone profile and $\sigma_{O 3}(T, \lambda)$ is approximated by a second 5 order polynomial in $T$, derived from the cross sections available at five temperatures.

The three cross sections $\sigma_{O 3}^{e l}, \sigma_{O 3}^{n s}$, and $\sigma_{O 3}^{s}$ are derived from a convolution with the broadened slit function, modulated by the solar spectrum, the Ring-broadened Solar spectrum and the Ring-broadened Solar spectrum multiplied by the cross sections of the Raman lines, respectively. This accounts for the solar $I_{0}$ effect (Aliwell et al., 2002).

\subsection{Implementation for SCIAMACHY}

Within the TOGOMI implementation for GOME special attention is paid to the level-1 data. Additional wavelength calibration, radiometric calibration, degradation correction and polarisation calibration are performed (Valks and van Oss, 2003). For the present TOSOMI implementation for SCIAMACHY no additional re-calibration for the ozone window (325-335nm) is applied, and the implementation directly uses the available level-1 data. Furthermore, no shift and squeeze operations are performed in the fitting algorithm. The processing is based on SCIAMACHY level 0 to 1 processor versions 4.00 (1 Jan. - 13 April 2003), 4.01 (13 April - 21 Sep. 2003), 4.03 (21 Sep. 2003 - 23 March 2004), 5.01 (23 March - 16 Aug. 2004), and 5.04 (16 Aug. 2004 March 2005).

The level-1 data resulting from the currently available processor versions is well known to have several problems. The major issue is the radiometric calibration: the reflectivities computed from the level 1 sun and earth spectra is off by about $20 \%$, and there are several other issues which need to be resolved such as polarisation.

25 Fortunately, the DOAS method is insensitive to radiometric calibration errors that are multiplicative and constant or slowly varying with wavelength. However, the method

\section{Retrieval and validation of \\ SCIAMACHY ozone columns}

H. J. Eskes et al.

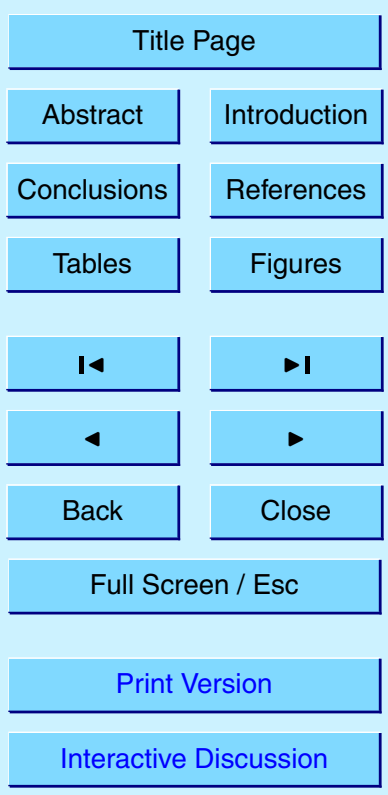

EGU 
is sensitive to additive radiometric errors (offsets). As will be shown in the validation results below, a good agreement is found between the SCIAMACHY and GOME retrievals. This indicates that the radiometric calibration problem is indeed mainly a multiplicative effect. Furthermore, the small fit residuals found (see Fig. 4) suggest that 5 the wavelength calibration is sufficient for the ozone retrieval. Note that the additional broadening applied will also reduce the sensitivity to small-scale calibration issues. The fit is satisfactory over the entire wavelength range of the fitting window, suggesting that the radiometric calibration issue is only slowly varying with wavelength.

For the FRESCO cloud retrieval additional calibration corrections are needed 10 (Fournier et al., 2004). In particular the cloud fraction is retrieved from the absolute reflectivity measured by SCIAMACHY. The radiometric calibration error is found to be quite stable, and to correct for this we introduce a crude correction factor of 1.25, applied to the radiances in the FRESCO window $(758-772 \mathrm{~nm})$. This factor was derived by comparing FRESCO results from GOME and SCIAMACHY that fly in the similar orbits about half an hour apart. The derived cloud fractions and cloud top pressures were binned on a $1 \times 1$ grid and were then compared. The SCIAMACHY radiances were adjusted such that the cloud parameters agree on average.

An example of one day of TOSOMI retrievals is shown in Fig. 5. This figure shows 14 orbits that have a scan width of about $960 \mathrm{~km}$. The gaps inside the orbits are due to the alternating limb/nadir measurement mode of SCIAMACHY. Each block in the figure consists of roughly 200 observations, with a smallest pixel size of $30 \times 60 \mathrm{~km}^{2}$, and one day has about 70000 measurements. Global coverage is obtained in about 6 days.

\subsection{Retrieval error estimates}

An error analysis has been presented for the OMI ozone DOAS product using simu25 lated spectra (Veefkind et al., 2002), and has been updated for the GOME instrument (Valks and van Oss, 2003). Most of the contributions to the retrieval error apply to the SCIAMACHY retrieval as well, and we refer the reader to these two papers for more details. Total errors are estimated to be of the order of $2.5-3.3 \%$. As mentioned

ACPD

$5,4429-4475,2005$

\section{Retrieval and validation of \\ SCIAMACHY ozone columns}

H. J. Eskes et al.

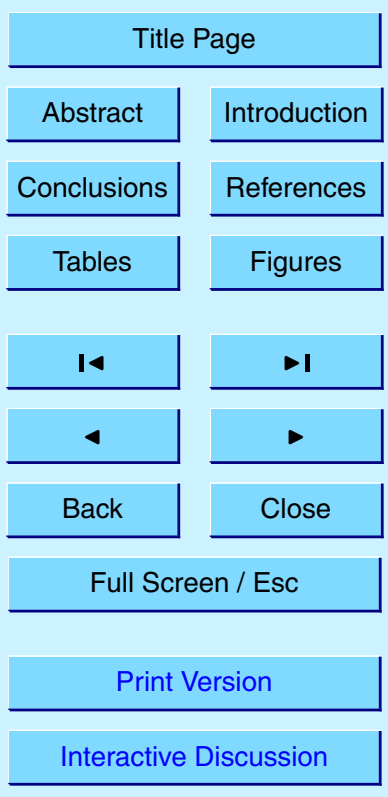

EGU 
above, one important source of absolute uncertainty (bias) is the choice of the ozone cross section. For extreme cases like desert dust and biomass burning events, polar stratospheric clouds, and solar zenith angles $>80^{\circ}$ larger errors may occur that reach up to $5 \%$.

\section{3. Validation with ground-based observations}

\subsection{Approach}

TOSOMI data from 2003 and 2004 were compared at seventy ground locations with ground-based Dobson (47), Brewer (22), or Filter (1) data. From the TOSOMI data, the nearest match for each individual ground measurements was selected, with a collocathon criterium of $100 \mathrm{~km}$ and $12 \mathrm{~h}$. For the ground data, daily averaged ozone columns were taken, with the exception of the De Bilt and Paramaribo sites, where the measurement closest in time to the SCIAMACHY overpass was taken.

Overpass data were taken from the daily averaged ozone summary file at the WOUDC database, except Paramaribo and De Bilt data, which were taken from daily 15 files stored in the NILU-Envisat validation database. Excluded from our comparison were stations that yielded fewer than twenty collocations with SCIAMACHY data, and two stations that from other satellite validation results were known to have large biases. No distinction between direct sun and zenith sky measurements was made.

\subsection{Validation results}

20 For each station, time-series of collocated SCIAMACHY and ground ozone columns, along with the percent differences, were made and plotted. From visual inspection we conclude that the overall ozone observations from the ground were well tracked by SCIAMACHY. Examples for the Arosa NH mid-latitude station, and the Syowa Antarctic station, are shown in Figs. 6 and 7. For Arosa we find a bias of $-0.7 \%$ and a rms of

\section{ACPD}

$5,4429-4475,2005$

\section{Retrieval and validation of \\ SCIAMACHY ozone columns}

H. J. Eskes et al.

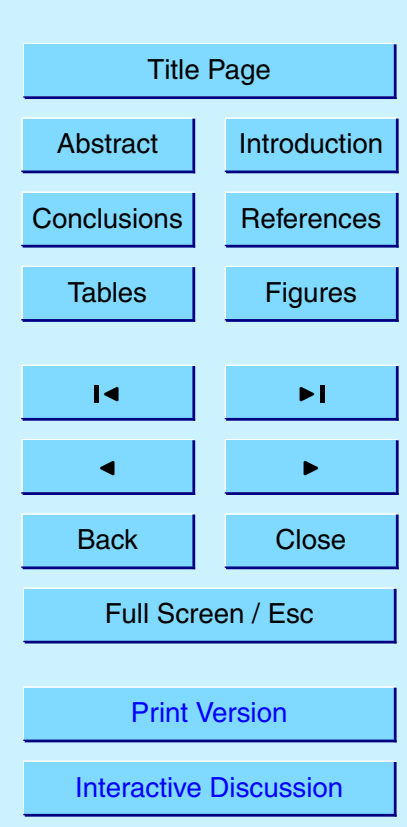


$4.2 \%$. For Syowa we find a bias of $-0.6 \%$ and a rms of $5.3 \%$. Arosa is a typical $\mathrm{NH}$ mid-latitude station, showing a large ozone variability in winter. Syowa shows a large dynamical range of ozone values due to the South Pole ozone hole, which is well captured by the TOSOMI observations.

$5 \quad$ Time series for all comparisons are plotted on a colour scale (where colour depicts percent difference between SCIAMACHY and ground based) as a function of month (horizontally), and binned into 10 deg latitude bins (vertically). Only months with four or more comparisons are plotted, as shown in Fig. 8.

The most statistically significant conclusion can be drawn from the results between 1030 and 60 deg north, where 42 ground instruments, more than half of all stations listed in Table 1, have been compared. There is a small seasonal difference in the comparison results, which range from about -3 to $+2 \%$. This may be due to a seasonal dependence of the Dobson and Brewer retrievals (Van Roozendael et al., 1998). There is no evidence for a latitudinal dependence in the TOSOMI-ground based comparison.

15 The dark blue patch in June/July of 2003 in the Arctic, is not statistically significant, since only one ground station is present in the 70-75 latitude bin (namely, Barrow at $71 \mathrm{~N}$ ), and the anomaly results from two measurement days during a time of fast ozone change.

Around the onset and end of the ozone hole over the Antarctic, TOSOMI data are clearly higher than groundbased measurements. It is unclear whether this is due to systematic effects in SCIAMACHY or the TOSOMI algorithm, or in the ground based Dobson measurements, or both. However, a recent study suggests that Dobson measurements underestimate ozone columns by $4 \%$ in ozone hole conditions for large solar zenith angles (Bernard et al., 2005). Similar differences have also been seen when other satellite data were compared with Dobson/Brewers (Lambert and Balis, 2004). The number of ground stations in these latitude bins is one (50-60 S, Ushuaia), two (60-70 S, Marambio and Syowa), and one (70-80 S, Arrival Heights). Light blue patches (about $-5 \%$ ) appear between months 7 and 10, and 18 and 21 , in the Southern Hemisphere at latitudes between 30 and $40 \mathrm{~S}$ (two stations) and 40 and $50 \mathrm{~S}$ (two

ACPD

$5,4429-4475,2005$

\section{Retrieval and validation of \\ SCIAMACHY ozone columns}

H. J. Eskes et al.

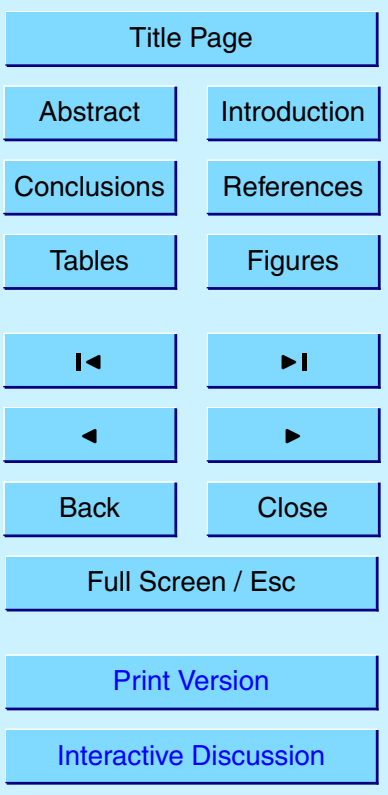

EGU 
stations).

The comparison series were averaged over time, for each of the stations. Results are plotted in Fig. 9. This figure shows that the bias between SCIAMACHY and ground based is, on average, $-1.7 \%$. There is no clear latitudinal dependence. The standard

5 deviation on the biases is, on average, $4.4 \%$. Here, it appears that the rms is smallest in the tropics, and increases towards the poles. This may be due to larger and quicker ozone variations towards the poles. Average numbers presented are the mean of all individual station's results. The same data as in the top panel of this figure are also shown on a world map, where biases are now shown in colours as presented in Fig. 10. 10 These data are tabulated in Table 1.

There is a good agreement between the validation results presented here and the validation reported for the TOGOMI GOME algorithm (Van Oss et al., 2004).

\section{Comparison with GOME retrievals}

The instruments GOME and SCIAMACHY were both operating with global coverage 15 until June 2003. At this time there was a tape malfunction on board ERS-2 and after June GOME is only able to transmit it's data when it is in direct sight of a ground station, which limits the coverage to the Arctic, Europe and North America. For SCIAMACHY, unfortunately, we have at present no continuous level-1 data set between launch and December 2002. As a result GOME and SCIAMACHY can be compared in the period 20 January-June 2003.

We compare the TOSOMI columns with two new ozone column data sets of GOME that have very recently become available. One is GDP-4 and the second is a GOME data set generated with the TOGOMI algorithm. The first is interesting because it is the last official release of the GOME total ozone product, based on a much improved DOAS algorithm (Lambert and Balis, 2004). The second is interesting because the TOGOMI and TOSOMI algorithms are nearly identical. The combination allows us to distinguish algorithm aspects from instrument aspects.

ACPD

$5,4429-4475,2005$

\section{Retrieval and validation of \\ SCIAMACHY ozone columns}

H. J. Eskes et al.

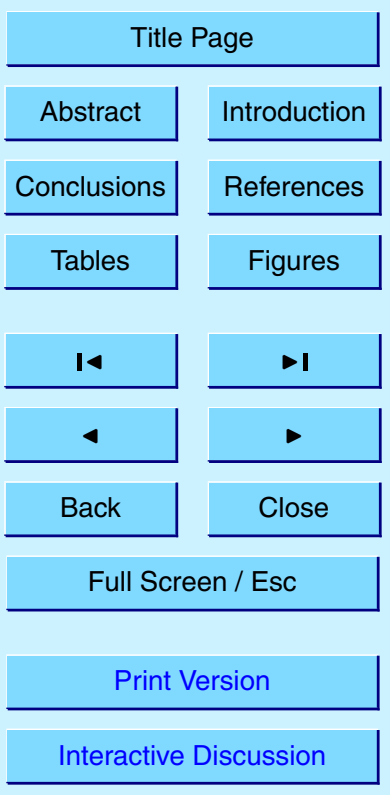

EGU 
The inter-comparison approach consists of the following steps. For a single day both GOME and SCIAMACHY ozone measurements are gridded on a fine 1 by 1 degree longitude-latitude grid. Next, for those grid cells that have both (at least) one SCIAMACHY and one GOME observation the difference is computed, and these dif5 ferences are subsequently averaged over longitude. This procedure is repeated for all the days and the results are plotted as a function of the day. The result is shown in Fig. 11.

The figure shows several features:

- There is an offset between the TOSOMI algorithm and both GDP-4 and TOGOMI. The bias with TOGOMI is $-1.3 \%$ (average for all latitudes between $60 \mathrm{~S}$ and $60 \mathrm{~N}$ ). For GDP-4 the bias is $-2.0 \%$ (60S-60N, excluding the last period). Combined it gives an average difference between GDP-4 and TOGOMI of $0.7 \%$.

- The time-space variability is small in both comparisons, apart from the highest latitudes. The standard deviation of the difference (TOSOMI-TOGOMI) around the mean is $0.9 \%(60 \mathrm{~S}-60 \mathrm{~N})$, demonstrating a high degree of consistency between GOME and SCIA. For (TOSOMI-GDP4) the standard deviation is $1.0 \%$. This is not much higher than for TOGOMI, showing the large degree of agreement between the GDP-4 and TOGOMI/TOSOMI DOAS algorithms.

- At the highest latitudes there are differences up to 3-5\% between TOSOMI and GDP-4. Here the differences between the algorithms are largest.

- Also the comparison with TOGOMI shows variability with latitude, e.g. low values around $45 \mathrm{~S}$, high values at large latitudes, with amplitude of a few \%. The reason for these differences is not clear, but may be related to large solar zenith angle conditions, South Atlantic Anomaly, and sampling differences.

- At the end of May 2003 there is a jump in the top panel. Because this jump is not seen in the lower panel we can attribute this to the GDP-4 product which shows a sudden overall increase in ozone of a few \%. Most likely, this effect is due to the
ACPD

5, 4429-4475, 2005

\section{Retrieval and validation of \\ SCIAMACHY ozone columns}

H. J. Eskes et al.

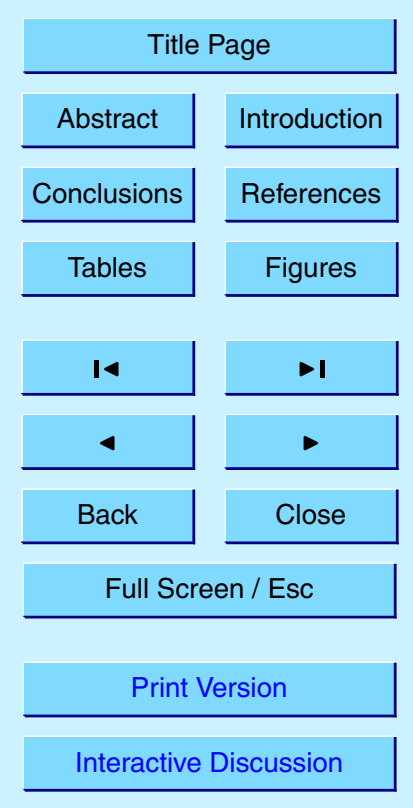

EGU 
unavailability of daily solar reference spectra in the GOME level-1 product after 23 May 2003.

\section{Validation with data assimilation}

The comparison with surface measurements reported above focusses mainly on bi5 latitude. The validation with data assimilation - reported in this section - is largely complementary. The assimilation incorporates the TOSOMI observations and absolute biases can not be reported. The comparison between the model short-term forecast and the retrieval is a sensitive tool to measure the (relative) dependence of the retrieval on retrieval parameters, like the satellite geometry, measurement mode (e.g. changes in measurement integration time) and cloud fraction. Because the model describes the main dynamical and chemical variability of the atmosphere, and because a model collocation exists for each retrieved ozone column, these relative errors can be derived with a high statistical significance.

\subsection{Assimilation approach}

The assimilation model TM3DAM (TM3 Data Assimilation Model) is described in detail in Eskes et al. (2003). The transport model is based on the second moment advection scheme and has 44 vertical levels and runs default with a resolution of $3 \times 2$ degree. The model is driven by the meteorological analyses of the European Centre for Medium-Range Weather Forecasts. Stratospheric ozone chemistry is described by two parametrisations, one for gas-phase chemistry and one for heterogeneous ozone loss in the polar regions. The assimilation uses a fast parameterised Kalman filter approach which provides ozone analyses and detailed forecast error estimates. Both observation-minus-forecast (OMF) and observation-minus-analysis data sets are routinely provided.
ACPD

5, 4429-4475, 2005

\section{Retrieval and validation of SCIAMACHY ozone columns}

H. J. Eskes et al.

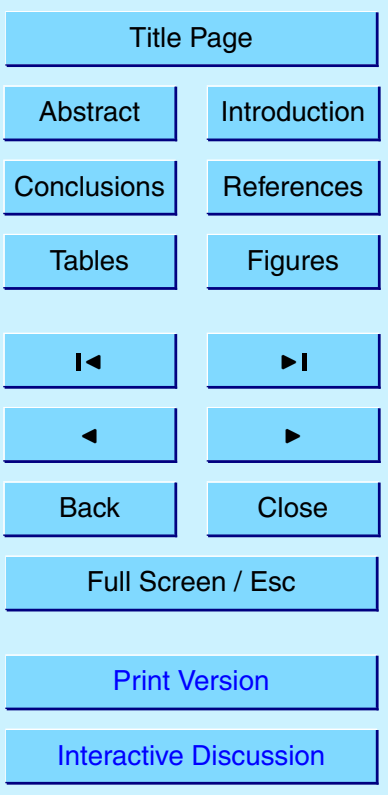

EGU 
The model assimilates TOSOMI near-real time ozone columns derived from the SCIAMACHY measurements. The data base of ozone analyses and daily ozone forecast are made available via the TEMIS project web site http://www.temis.nl/.

\subsection{Verification during algorithm development}

5 Data assimilation has been used extensively during the development of the TOSOMI implementation (which consisted of the adaptation of the TOGOMI algorithm for SCIAMACHY). When a new version of the retrieval became available we processed one month of data, assimilated this data set and inspected the OMF residuals. A new version of TOSOMI was subsequently introduced to correct for the problems detected.

10 This cycle was repeated about four times, leading to the current Version 0.32.

Problems detected in this way were related to satellite geometry (solar zenith and viewing angle), ground-pixel co-ordinates, cloud retrieval and the representation of the lookup table. As example we show the solar zenith angle dependence of OMF for TOSOMI Version 0.3. This showed pronounced features for solar zenith angles between 75 and $85 \mathrm{deg}$. The minima correspond to entries in the AMF lookup table of Version 0.3 , which allowed us to identify the problem. The AMF lookup table of Version 0.3 stores AMF values relative to a simple geometrical AMF scaling with $1 / \cos \theta_{0}$. This choice introduces considerable curvature for values of $\theta_{0}>75^{\circ}$. A theoretical estimate of the resulting error is also shown in Fig. 12. The correspondence between 20 the two curves is striking, demonstrating the capability of the assimilation to detect detailed retrieval artefacts. Note that on average the assimilation analysis/forecast adopts the mean of the ozone column measurements, turning the positive errors into negative OMF residuals. In Version 0.32 the AMF lookup table is defined with respect to a geometrical AMF that accounts for the earth's curvature. In this way the relative AMF 25 values stay close to 1 also for large SZAs and interpolation errors are reduced to half a percent or less.

\section{ACPD}

$5,4429-4475,2005$

\section{Retrieval and validation of SCIAMACHY ozone columns}

H. J. Eskes et al.

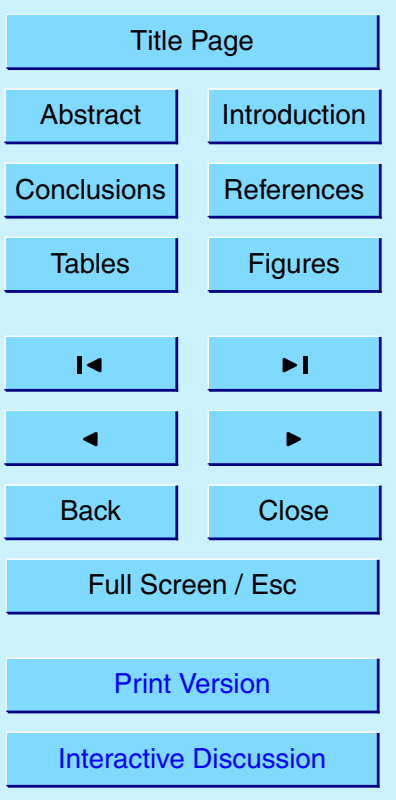


The OMF comparisons are related to short-range forecast periods of about two to six days. This is due to the time between observations related to the global coverage of SCIAMACHY which is obtained after 6 days for low latitudes, and a few days (depend5 ing on the season) at high latitudes where the orbits of Envisat come close and start to overlap. Because of this the observations and model forecast can be considered independent when probing time scales of several days or shorter, and for corresponding length scales. The OMF residuals are able to detect rapid variability in space (e.g. surface albedo variation, viewing angle dependence) and time (e.g. dependence of the 10 retrieval on clouds). Longer-range (long-term) changes in ozone (e.g. mean ozone concentration) are efficiently assimilated.

A monthly mean plot of the latitude dependence of OMF demonstrates the performance of the model. On the time scales of 2-6 days the model is able to predict the next observation with an accuracy of 8-9 DU on average, or about 3\%. This is shown in

15 Fig. 13. Note that the standard deviation of OMF consists of three contributions: model forecast errors, retrieval noise and a representativeness error describing the difference in ozone mass between the model grid box and the satellite ground pixel. A conservative estimate of the retrieval noise is then $2 \%$ or less. By changing the ratio between the model error and retrieval error in the assimilation we find the best forecasts when assuming the model error being larger than the retrieval noise. This suggests that $1 \%$ or less is a more realistic estimate of the retrieval noise. This would confirm the small uncertainty estimate derived from the fit residuals.

The monthly mean bias as a function of latitude is typically less than $1 \%$ demonstrating how the model incorporates the information of the observations. Comparing the figure with plots of other months we find that the biases and standard deviations are typically somewhat larger near the pole where the light returns (e.g. high northern latitudes in March). In September this is observed for latitudes near 60S. This can be expected, since the observations at the end of the tracks probe ozone values that have

\section{Retrieval and validation of SCIAMACHY ozone columns}

H. J. Eskes et al.

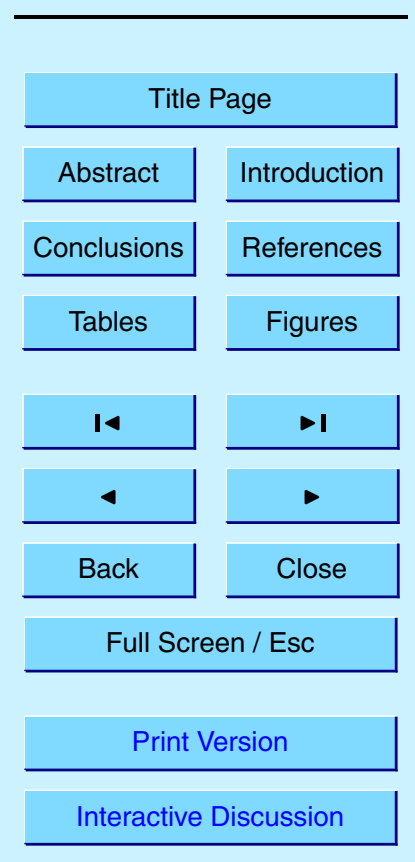


not been observed for a long time, and model errors will have built up above the winter pole.

The 2-D distribution of monthly-mean OMF values is shown in Fig. 14. There are several things to note. First, most of the plot is light-green, indicating that OMF does 5 not exceed 5DU (or about 1-2\%) for most grid boxes. In comparison with the previous section this shows that deviations of individual model forecasts with the retrieval has a much smaller spread than the differences between the retrieval and groundbased measurements. Second, there are no very obvious surface albedo-related effects (land-sea jumps, desert). This is a pleasing result, because the retrieval depends 10 significantly on e.g. the surface reflectivity. Third, there are no obvious jumps in latitude. Such jumps could possibly be caused by the different measurement modes (state identifiers) which have different integration times, related to the solar zenith angle (or latitude). Furthermore, the large changes in the ozone distribution between subtropics and mid-latitudes is not reflected in OMF, which is a good result.

15 There are two features that seem to be significant. The positive OMF above Greenland, about $4-5 \%$, is observed in other months as well. Another positive OMF difference is observed in the South Atlantic, near the vortex edge. In both cases it is difficult to judge whether the model transport is biased (orography, vortex dynamics), or if it is a retrieval issue (possibly related to altitude, surface albedo, or profile shape near the 20 vortex edge).

\subsection{Retrieval parameter dependence}

Figure 15 shows the viewing angle dependence of OMF. A first thing to note is that on average the ozone values of TOSOMI are roughly independent on the viewing angle to within $1 \%$. However, the plot shows several characteristic features, with amplitudes 25 of 1-2 DU, which are reproducible from one month to the next, with an evolution over time. The results for two months are shown, one at the beginning (SCIAMACHY L1 processor 4.00) and one at the end (SCIAMACHY L1 processor 5.04) of the 2003/2004 data set. Other months show a behaviour intermediate to the ones shown here.

ACPD

$5,4429-4475,2005$

\section{Retrieval and validation of SCIAMACHY ozone columns}

H. J. Eskes et al.

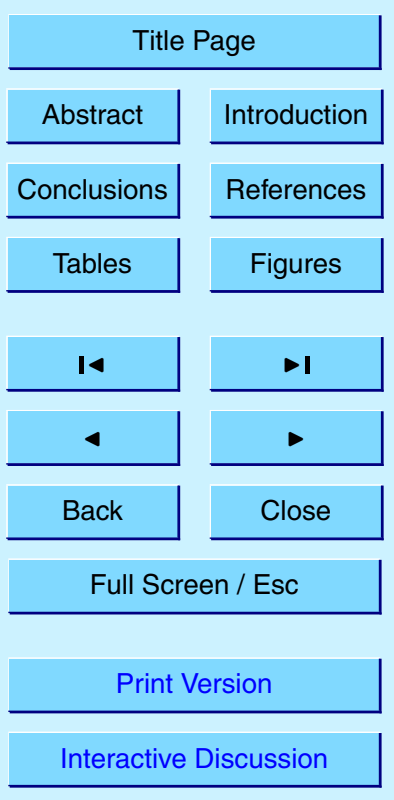

EGU 
(i) The forward scan ozone values are increasing, and the back-scans are decreasing as a function of the viewing angle. This effect is understood and is most probably related to the read-out time delay of the detector which results in a slight shift of the actual viewing angle compared to the reported one. This effect will be incorporated in the next version of TOSOMI.

(ii) The forward scan ozone values of state 6 seem to be clustered in groups of four, with ozone retrievals of the first one systematically higher than the other three. This effect was hardly visible early 2003 , but became more pronounced in 2004 and with successive processor upgrades. An explanation of this effect is not known to us at present.

(iii) The first pixel of the forward scan of state 7 is systematically higher than the others. Again the effect increased over time and may well be related to the effect seen for state 6 .

The dependence of the total column of ozone on the cloud fraction produced by the FRESCO algorithm is shown in Fig. 16. The shape, with a minimum for cloud fractions between 0.5 and 0.7 and maxima for cloud fractions 0 and 1 is characteristic also for other months. The relative ozone difference between cloud fraction 0 and 1 depends somewhat on the month and on the state identifier. The range of OMF values is about 2 DU, less than $1 \%$.

\section{Conclusions}

In this paper we have presented the implementation and validation results for the TOSOMI algorithm to retrieve ozone columns based on the SCIAMACHY measurements. Fits of high precision are obtained in the $325-335 \mathrm{~nm}$ ozone fit window based on the currently processed level-1 data. The TOSOMI algorithm is shown to be quite insensitive to the consecutive upgrades of the level-1 products for SCIAMACHY in the years 2003 and 2004.

ACPD

5, 4429-4475, 2005

\section{Retrieval and validation of SCIAMACHY ozone columns}

H. J. Eskes et al.

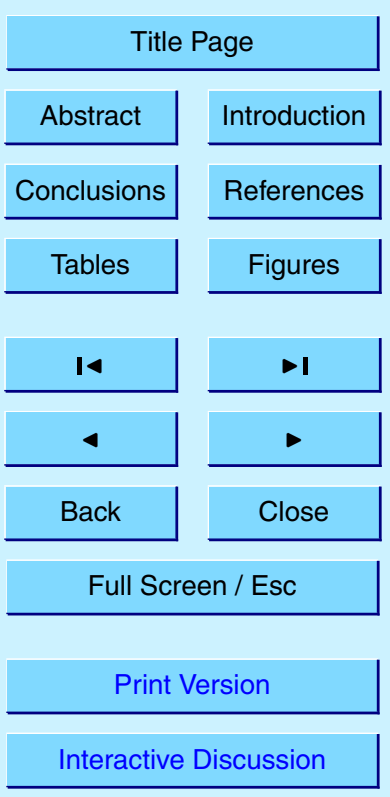

EGU 
The validation exercises show an offset of about $-1.5 \%$ as compared to GOME retrievals and ground-based observations. The TOSOMI Version 0.32 implementation discussed here is based on broadened GOME Flight Model cross sections applied to SCIAMACHY. One motivation for this initial choice is that we wanted to keep as close 5 as possible to the implementation for GOME, to be able to detect differences between the SCIAMACHY and GOME instruments. Possible reasons for the $-1.5 \%$ offset are (i) uncertainties in the GOME and SCIA slit function representation used in the effective cross section calculations, and (ii) the problems with the radiometric calibration of SCIAMACHY. A more logical choice is the use of Bass-Paur ozone cross sections. 10 These are available in high resolution which allows us to perform the cross section convolutions more accurately. In fact, we find slightly better fit residuals when Bass-Paur is used. This choice will change the offset by several percent. Given the cross section uncertainties it seems justified to introduce a constant scaling factor on the cross sections to account for the offset. These are considerations for the next upgrade of 15 TOSOMI.

Apart from the offset we find good correspondence between TOSOMI and GOMETOGOMI and GOME-GDP4. The root-mean-square differences between these ozone retrievals is of the order of only $1 \%$ over a 5 -month period and binned daily on 1 deg latitude strips. This result is in agreement with the high degree of consistency between the TOSOMI columns and the short-range ozone forecast of our data assimilation model. However, the comparison also suggests some systematic differences compared to GOME with an amplitude of one percent, and differences at high solar zenith angles of several percent which are not explained at the moment.

The root-mean square differences with the ground-based Brewer-Dobson data sets 25 are much larger than the differences found in the GOME comparison. In our comparisons we have minimised mismatches in observed airmasses by using a tight collocation criterion of $100 \mathrm{~km}$. The TOSOMI retrieval is found to be $-1.7 \%$ lower than ground-based observations on average, but with a large variability from one station to the next. At least part of the variability and seasonal dependence observed may be at-
ACPD

$5,4429-4475,2005$

\section{Retrieval and validation of \\ SCIAMACHY ozone columns}

H. J. Eskes et al.

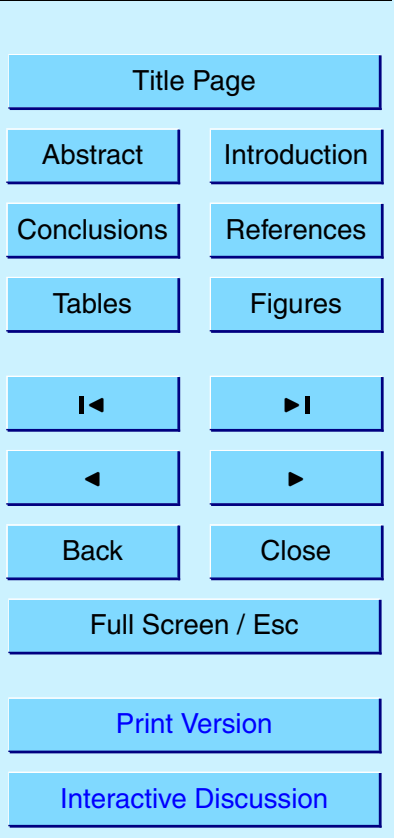


tributed to the surface observations. For Dobson instruments a reproducibility of $2 \%$ is typically mentioned, but systematic errors may be of the order of $4-5 \%$ with a seasonal dependence of a few \% (Van Roozendael et al., 1998). During ozone hole conditions

Dobson instruments may underestimate total ozone by up to $4 \%$ (Bernard et al., 2005).

5 Such inaccuracies are due to the choice of one fixed temperature and fixed ozone profile shape in the retrieval for the ground observations. The comparison seems to be roughly latitude independent to within the estimated accuracy of the ground measurements (2-3\%). For more accurate conclusions it is crucial to study the individual ground measurements concerning measurement conditions and retrieval procedure (Lambert 10 et al., 2004).

Several of the detailed changes (with amplitude $<1 \%$ ) observed as a function of the viewing angle can be understood in terms of small inaccuracies in the specification of the viewing geometry. These features are also changing with time. The effects which are understood will be corrected for in a next upgrade of TOSOMI. The FRESCO cloud algorithm has also been improved by means of a new surface albedo map, with a positive impact on the cloud fraction retrieval especially for desert areas. A TOSOMI reprocessing is foreseen as soon as a new and consistent processing of the entire SCIAMACHY level-1 data set becomes available.

The good correspondence between the GOME and SCIAMACHY retrievals provides

prospects for combining the data of both instruments into a homogeneous global total ozone data set which spans about 10 years.

Acknowledgements. We acknowledge the use of ground-based ozone column observations from the WOUDC and Envisat-NILU databases. The financial support by the Netherlands Agency for Aerospace Programmes (NIVR) is gratefully acknowledged.

\section{References}

Aliwell, S. R., Van Roozendael, M., Johnston, P. V., Richter, A., Wagner, T., Arlander, D. W., Burrows, J. P., Fish, D. J., Jones, R. L., Tørnkvist, K. K., Lambert, J.-C., Pfeilsticker, K., and

\section{Retrieval and validation of SCIAMACHY ozone columns}

H. J. Eskes et al.

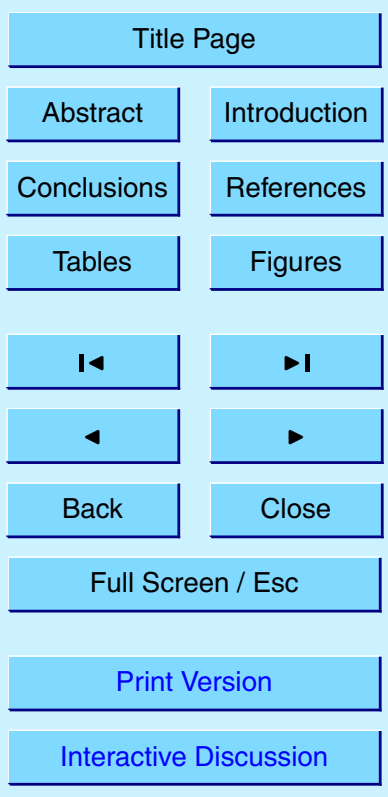

EGU 
Pundt, I.: Analysis for BrO in zenith-sky spectra: An intercomparison exercise for analysis improvement, J. Geophys.Res., 107, doi:10.1029/2001JD000329, 2002. 4440

Bass, A. M. and Paur, R. J.: The ultraviolet cross-sections of ozone, I. The measurements, II - Results and temperature dependence, in: Proc. Quadrennial Ozone Symp., Chalkidiki,

$5 \quad$ Greece, edited by: Zefros, C. and Ghazi, A., Reidel, Dordrecht, 606, 1986. 4439

Bernard, G., Evans, R. D., Labow, G. J., and Oltmans, S. J.: Bias in Dobson total ozone measurements at high latitudes due to approximations in calculations of ozone absorption coefficients and airmass, accepted for publication in J. Geophys. Res., 2005. 4443, 4452

Bhartia, P. K. and Wellemeyer, C. W.: TOMS v8 Algorithm Theoretical Basis Document, http: //toms.gsfc.nasa.gov/version8/v8toms_atbd.pdf, NASA, 2004. 4430, 4431, 4433, 4437

Bhartia, P. K., McPeters, R. D., Mateer, C. L., Flynn, L. E., and Wellemeyer, C.: Algorithm for the estimation of vertical ozone profile from the backscattered ultraviolet (BUV) technique, J. Geophys. Res., 101, 18793-18806, 1996. 4430

Bogumil, K., Orphal, J., Homann, T., Voigt, S., Spietz, P., Fleischmann, O. C., Vogel, A., Hartmann, M., Bovensmann, H., Frerick, J., and Burrows, J. P.: Measurements of molecular absorption spectra with the SCIAMACHY Pre-Flight Model: instrument characterization and reference data for atmospheric remote-sensing in the $230-2380 \mathrm{~nm}$ region, Journal of Photochemistry and Photobiology A: Chemistry 157, 167-184, 2003. 4438

Bovensmann, H., Burrows, J. P., Buchwitz, M., Frerick, J., Noël, S., Rozanov, V. V., Chance, K. V., and Goede, A. P. H.: SCIAMACHY: Mission objectives and measurement modes, J. Atmos. Sci., 56, 127-150, 1999. 4431

Burrows, J. P., Weber, M., Buchwitz, M., Rozanov, V., Ladstätter-Weibenmayer, A., Richter, A., Debeek, R., Hoogen, R., Bramstedt, K., Eichmann, K.-U., Eisinger, M., and Perner, D.: The Global Ozone Monitoring Experiment (GOME): Mission concept and first results, J. Atmos. Sciences, 56, 151-175, 1999a. 4431

Burrows, J. P., Richter, A., Dehn, A., Deters, B., Himmelmann, S., Voigt, S., and Orphal, J.: Atmospheric remote-sensing reference data from GOME -2 . Temperature-dependent absorption cross sections of $\mathrm{O} 3$ in the $231-794 \mathrm{~nm}$ range, Journal of Quantitative Spectroscopy \& Radiative Transfer, 61, 509-517, 1999b. 4438

30 Chance, K. and Spurr, R. J. D.: Ring Effect Studies: Rayleigh Scattering, Including Molecular Parameters for Rotational Raman Scattering, and the Fraunhofer Spectrum, Applied Optics 36, 5224-5230, 1997. 4435

Coldewey-Egbers, M., Weber, M., Lamsal, L. N., de Beek, R., Buchwitz, M., and Burrows,

\section{Retrieval and validation of \\ SCIAMACHY ozone columns}

H. J. Eskes et al.

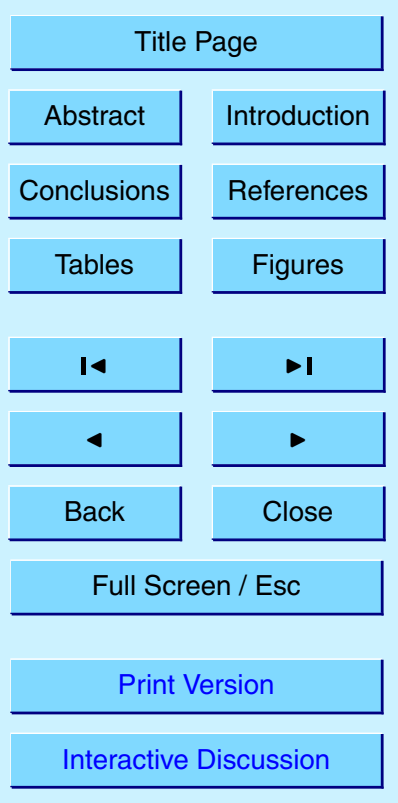

EGU 
J. P.: Total ozone retrieval from GOME UV spectral data using the weighting function DOAS approach, Atmos. Chem. Phys., 5, 1015-1025, 2005,

SRef-ID: 1680-7324/acp/2005-5-1015. 4431, 4433, 4435

De Haan, J. F., Bosma, P. B., and Hovenier, J. W.: The adding method for multiple scattering calculations of polarized light, Astron. Astrophys., Vol. 183, 371-391, 1987. 4433, 4437

De Haan, J. F.: Accounting for Raman Scattering in DOAS, Version 1.0, OMI technical report SN-OMIE-KNMI-409, KNMI, http://www.gse-promote.org/services/ozone_nrt/DeHaan_OMI Raman_DOAS_v_1.pdf, 2003. 4433, 4435

Dethof, A. and Hólm, E.: Ozone assimilation at ECMWF, Q. J. R. Meteorol. Soc., 130, 28512872, 2004. 4432

Eskes, H. J., van Velthoven, P. F. J., Valks, P. J. M., and Kelder, H. M.: Assimilation of GOME total ozone satellite observations in a three-dimensional tracer transport model, Q. J. R. Meteorol. Soc., 129, 1663-1681, 2003. 4432, 4446

Eskes, H. J. and Dethof, A.: Sciamachy ozone column validation with models and assimilation,

15 Proceedings of the second workshop on the Atmospheric Chemistry Validation of Envisat (ACVE-2), 3-7 May, 2004.

Fournier, N., Stammes, P., Acarreta, J. R., Eskes, H., Piters, A., Hess, M., von Bargen, A., Kokhanovsky, A., and Grzegorski, M.: SCIAMACHY cloud product validation, Proceedings of the second workshop on the Atmospheric Chemistry Validation of Envisat (ACVE-2), 3-7

20 May, 2004. 4437, 4441

Herman, J. R. and Celarier, E. A.: Earth surface reflectivity climatology at $340-380 \mathrm{~nm}$ from TOMS data, J. Geophys. Res., 102, 28 003-28 011, 1997. 4437

Koelemeijer, R. B. A., Stammes, P., Hovenier, J. W., and de Haan, J. F.: A fast method for retrieval of cloud parameters using oxygen A-band measurements from GOME, J. Geophys. Res., 106, 3475-3490, 2001. 4432, 4437

Lambert, J.-C., Allaart, M., Andersen, S. B., Blumenstock, T., Bodeker, G., Brinksma, E., Cambridge, C., De Mazière, M., Demoulin, P., Gerard, P., Gil, M., Goutail, F., Granville, J., Ionov, D. V., Kyrö, E., Navarro-Comas, M., Piters, A., Pommereau, J.-P., Richter, A., Roscoe, H. K., Schets, H., Shanklin, J. D., Suortti, T., Sussmann, R., Van Roozendael, M., Varotsos, C., Wagner, T., Wood, S., and Yela, M.: First ground-based validation of SCIAMACHY v5.01 ozone column, Proceedings of the second workshop on the Atmospheric Chemistry Validation of Envisat (ACVE-2), 3-7 May, 2004. 4452

Lambert, J.-C. and Balis, D.: Delta validation report for ERS-2 GOME Data Processor

ACPD

5, 4429-4475, 2005

\section{Retrieval and validation of \\ SCIAMACHY ozone columns}

H. J. Eskes et al.

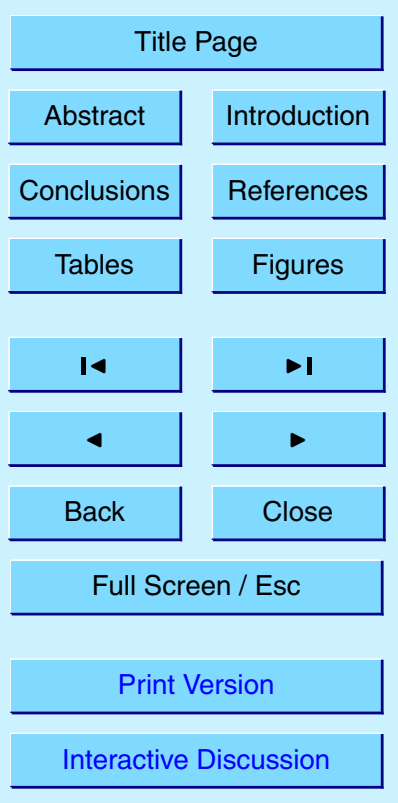

EGU 
upgrade to version 4.0, ERSE-CLVL-EOPG-TN-04-0001, Version 1.0, http://wdc.dlr.de/ sensors/gome/gdp4/validation.pdf, ESA, December 2004. 4443, 4444

Marquard, L. C., Wagner, T., and Platt, U.: Improved air mass factor concepts for scattered radiation differential optical absorption spectroscopy of atmospheric species, J. of Geophys.

5 Res., 105, 1315, 2000. 4433, 4436

Orphal, J.: A critical review of the absorption cross-sections of O3 and NO2 in the 240-790 nm region, ESA Technical Note MO-TN-ESA-GO-0302, 2002. 4439

Spurr, R. J. D., van Roozendael, M., and Loyola, D. G.: Algorithm Theoretical Basis Document for GOME Total Column Densities of Ozone and Nitrogen Dioxide UPAS/GDOAS: GDP 4.0, DLR Technical note ERSE-DTEX-EOPG-TN-04-0007, issue 1A, Oberpfaffenhofen, Germany, December, http://earth.esa.int/pub/ESA_DOC/GOME/ATBD.pdf, 2004. 4431

Valks, P., and R. van Oss, TOGOMI Algorithm Theoretical Basis Document, Issue 1.2, TOGOMI/KNMI/ATBD/001, KNMI/ESA, November 2003, http://www.gse-promote.org/services/ ozone_nrt/togomi_ATBD_v1.21.pdf. 4431, 4432, 4438, 4439, 4440, 4441

15 van Oss, R. F., Valks, P. J. M., and de Haan, J. F.: TOGOMI Delta Validation Document, TOGOMI/KNMI/VAL/002, KNMI/ESA, January 2004, http://www.gse-promote.org/services/ ozone_nrt/togomi_deltavalidation_v1.0.pdf, 2004. 4444

Van Roozendael, M., Peeters, P., Roscoe, H. K., de Backer, H., Jones, A. E., Bartlett, L., Vaughan, G., Goutail, F., Pommereau, J.-P., Kyro, E., Wahlstrom, C., Braathen, G., and Simon, P. C.: Validation of ground-based visible measurements of total ozone by comparison with Dobson and Brewer spectrophotometers, J. Atmosp. Chem., 29, 55-83, 1998.4443 , 4452

Van Roozendael, Soebijanta, V., Fayt, C., and Lambert, J.-C.: Investigation of DOAS issues affecting the accuracy of the GDP Version 3.0 total ozone product, in ERS-2 GOME GDP 3.0 Implementation and Delta Validation Report, ERSE-DTEX-EOAD-TN-02-0006, Issue 1.0, http://earth.esrin.esa.it/pub/ESA_DOC/GOME/gdp3/gdp3.pdf, 2002. 4435, 4439

Veefkind, J. P. and de Haan, J. F.: OMI Algorithm Theoretical Basis Document, Volume II, Chapter 3, DOAS Total Ozone Algorithm, ATBD-OMI-02, Version 2.0, August 2002, edited by: Barthia, P. K., http://www.knmi.nl/omi/documents/data/OMI_ATBD_Volume_2_V2.pdf, 2002. 4431, 4432, 4433, 4436, 4438, 4441

Veefkind, J. P., de Haan, J. F., Brinksma, E. J., Kroon, M., and Levelt, P. F.: Total ozone from the ozone monitoring instrument (OMI) using the DOAS technique, submitted to IEEE Transactions on Geoscience and Remote Sensing, preprint 2005. 4432, 4436

\section{Retrieval and validation of \\ SCIAMACHY ozone columns}

H. J. Eskes et al.

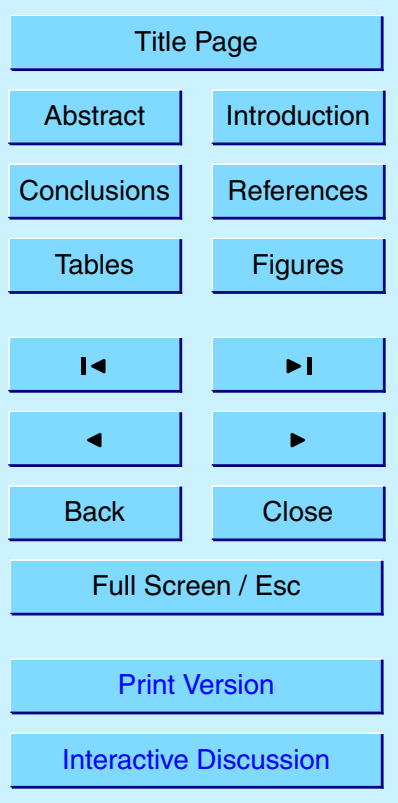

EGU 
Vountas, M., Rozanov, V. V., and Burrows, J. P.: Ring Effect: Impact of rotational Raman scattering on radiative transfer in Earth's Atmosphere, Journal of Quantitative Spectroscopy and Radiative Transfer, Vol. 60, No. 6, 943-961, 1998. 4435

Weber, M., Lamsal, L. N., Coldewey-Egbers, M., Bramstedt, K., and Burrows, J. P.: Pole-to-pole validation of GOME WFDOAS total ozone with groundbased data, Atmos. Phys. Chem. Dis., 4, 6909-6941, 2004. 4431

WMO: WMO Scientific Assessment of Ozone Depletion: 2002, WMO-GAW report, 2003. 4430

\section{ACPD}

5, 4429-4475, 2005

\section{Retrieval and validation of SCIAMACHY ozone columns}

H. J. Eskes et al.

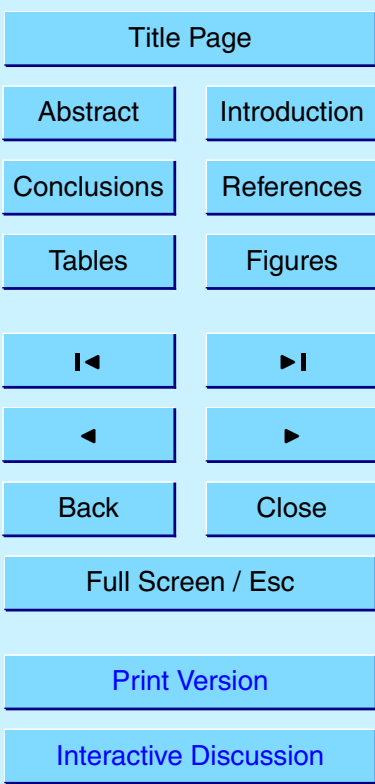


Table 1. List of stations included in the comparison with SCIAMACHY, their location, instrument type, bias and standard deviation with respect to the TOSOMI retrieval, the correlation coefficient and the number of intercomparisons.

\begin{tabular}{crrlrllr}
\hline location & lat & lon & instrument & bias & rms & corcoef & num \\
\hline Arrival Heights & -77.83 & 166.67 & Dobson & -0.85 & 7.07 & 0.85 & 81 \\
Syowa & -69.00 & 39.58 & Dobson & -0.57 & 5.30 & 0.94 & 205 \\
Marambio & -64.23 & -56.72 & Dobson & 1.27 & 5.69 & 0.93 & 84 \\
Ushuaia & -54.85 & -68.31 & Dobson & -0.41 & 5.30 & 0.88 & 184 \\
Comodoro Rivadavia & -45.78 & -67.50 & Dobson & -2.40 & 5.18 & 0.81 & 171 \\
Lauder & -45.03 & 169.68 & Dobson & -3.15 & 5.10 & 0.88 & 71 \\
Buenos Aires & -34.58 & -58.48 & Dobson & -2.94 & 4.47 & 0.82 & 112 \\
Perth & -31.92 & 115.95 & Dobson & -3.79 & 4.34 & 0.94 & 101 \\
Springbok & -29.67 & 17.90 & Dobson & -6.72 & 6.73 & 0.88 & 164 \\
Irene & -25.56 & 28.19 & Dobson & -3.54 & 3.92 & 0.88 & 119 \\
Samoa & -14.25 & -170.56 & Dobson & -1.36 & 2.42 & 0.57 & 67 \\
Singapore & 1.33 & 103.88 & Dobson & -1.43 & 2.60 & 0.84 & 95 \\
Petaling Jaya & 3.10 & 101.65 & Brewer & -2.42 & 2.71 & 0.88 & 123 \\
Paramaribo & 5.81 & -55.21 & Brewer & -0.85 & 2.76 & 0.81 & 142 \\
Bangkok & 13.67 & 100.61 & Dobson & -0.44 & 2.50 & 0.92 & 64 \\
Poona & 18.53 & 73.85 & Dobson & -2.86 & 2.91 & 0.95 & 26 \\
Mauna Loa & 19.53 & -155.57 & Dobson & 2.70 & 2.79 & 0.94 & 55 \\
Tamanrasset & 22.80 & 5.52 & Dobson & -0.67 & 1.73 & 0.90 & 141 \\
Aswan & 23.97 & 32.78 & Dobson & -3.31 & 3.54 & 0.91 & 145 \\
Kunming & 25.03 & 102.68 & Dobson & -1.25 & 2.00 & 0.96 & 64 \\
Varanasi & 25.32 & 83.03 & Dobson & 0.68 & 2.59 & 0.79 & 113 \\
Naha & 26.20 & 127.68 & Dobson & -2.70 & 3.21 & 0.93 & 144 \\
Hurghada & 27.28 & 33.75 & Dobson & -3.56 & 4.71 & 0.70 & 151 \\
New Delhi & 28.65 & 77.22 & Dobson & -3.17 & 3.78 & 0.77 & 128 \\
Cairo & 30.08 & 31.28 & Dobson & -3.14 & 4.35 & 0.79 & 184 \\
\hline
\end{tabular}

ACPD

$5,4429-4475,2005$

\section{Retrieval and validation of SCIAMACHY Ozone columns}

H. J. Eskes et al.

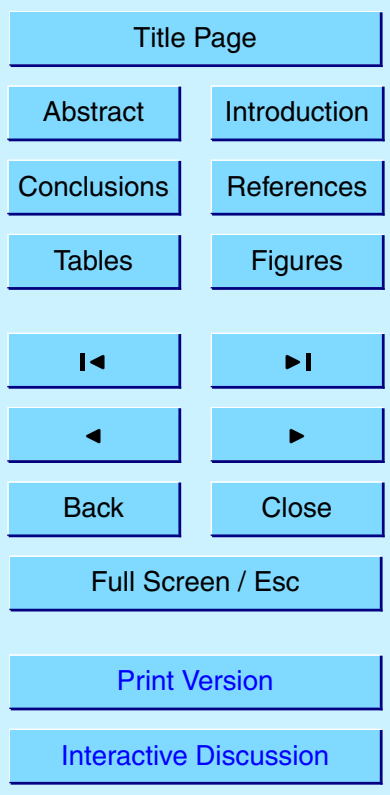

EGU 


\section{ACPD}

Table 1. Continued.

5, 4429-4475, 2005

\begin{tabular}{crrlrllr}
\hline location & lat & lon & instrument & bias & rms & corcoef & num \\
\hline Quetta & 30.11 & 66.57 & Dobson & -3.09 & 4.46 & 0.46 & 106 \\
Linan & 30.30 & 119.73 & Brewer & -1.49 & 4.17 & 0.79 & 83 \\
Kagoshima & 31.58 & 130.57 & Dobson & -0.91 & 4.01 & 0.85 & 149 \\
Isfahan & 32.48 & 51.42 & Brewer & -3.58 & 5.15 & 0.67 & 166 \\
Tateno Tsukuba & 36.06 & 140.10 & Dobson & -2.26 & 4.92 & 0.86 & 157 \\
Mt Waliguan & 36.17 & 100.53 & Brewer & 0.49 & 3.65 & 0.79 & 115 \\
Nashville & 36.25 & -86.57 & Dobson & -0.59 & 3.74 & 0.83 & 81 \\
Hanford & 36.32 & -119.63 & Dobson & -0.70 & 4.24 & 0.84 & 88 \\
El Arenosillo & 37.10 & -6.73 & Brewer & -1.90 & 4.14 & 0.84 & 160 \\
El Arenosillo & 37.10 & -6.73 & Dobson & -0.83 & 4.03 & 0.84 & 59 \\
Wallops Island & 37.93 & -75.48 & Dobson & -1.29 & 4.01 & 0.86 & 34 \\
Murcia & 38.00 & -1.17 & Brewer & -3.27 & 4.54 & 0.87 & 115 \\
Goddard & 38.99 & -76.83 & Brewer & -3.84 & 6.17 & 0.75 & 120 \\
Xianghe & 39.97 & 116.37 & Dobson & -3.92 & 6.43 & 0.78 & 116 \\
Boulder & 40.03 & -105.25 & Dobson & 1.13 & 4.05 & 0.85 & 81 \\
Amberd & 40.38 & 44.25 & Dobson & 0.77 & 4.83 & 0.73 & 71 \\
Sapporo & 43.06 & 141.33 & Dobson & -2.33 & 5.42 & 0.87 & 167 \\
Haute Provence & 43.93 & 5.70 & Dobson & -1.83 & 5.04 & 0.86 & 72 \\
Bucharest & 44.48 & 26.13 & Dobson & -0.82 & 4.59 & 0.87 & 131 \\
Longfengshan & 44.75 & 127.60 & Brewer & -2.47 & 5.60 & 0.87 & 105 \\
JRC Ispra Varese & 45.80 & 8.63 & Brewer & -2.63 & 5.08 & 0.86 & 178 \\
Bismarck & 46.77 & -100.75 & Dobson & -0.44 & 4.02 & 0.88 & 121 \\
Arosa & 46.78 & 9.68 & Brewer & -0.66 & 4.16 & 0.88 & 177 \\
Arosa & 46.78 & 9.68 & Dobson & 2.12 & 4.32 & 0.87 & 156 \\
Caribou & 46.87 & -68.03 & Dobson & -1.88 & 5.79 & 0.66 & 49 \\
\hline & & & & & & &
\end{tabular}

\section{Retrieval and validation of SCIAMACHY ozone columns}

H. J. Eskes et al.

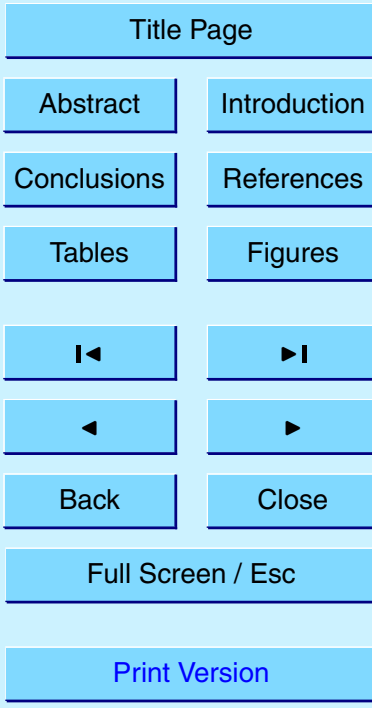

Interactive Discussion 


\section{ACPD}

Table 1. Continued.

\begin{tabular}{crrlrllr}
\hline location & lat & lon & instrument & bias & rms & corcoef & num \\
\hline Budapest Lorinc & 47.43 & 19.18 & Brewer & -2.92 & 3.97 & 0.94 & 154 \\
Hohenpeissenberg & 47.80 & 11.02 & Brewer & -0.72 & 3.92 & 0.89 & 182 \\
Hohenpeissenberg & 47.80 & 11.02 & Dobson & -0.40 & 3.75 & 0.91 & 122 \\
Poprad-Ganovce & 49.03 & 20.32 & Brewer & -0.48 & 3.94 & 0.91 & 227 \\
Hradec Kralove & 50.18 & 15.83 & Brewer & -2.01 & 4.69 & 0.87 & 223 \\
Hradec Kralove & 50.18 & 15.83 & Dobson & -0.63 & 3.98 & 0.89 & 164 \\
Camborne & 50.22 & -5.32 & Dobson & -2.64 & 4.44 & 0.93 & 66 \\
Uccle & 50.80 & 4.35 & Brewer & -1.49 & 4.42 & 0.88 & 185 \\
Uccle & 50.80 & 4.35 & Dobson & -0.24 & 4.10 & 0.91 & 128 \\
Valentia & 51.93 & -10.25 & Brewer & -3.18 & 5.40 & 0.58 & 10 \\
De Bilt & 52.10 & 5.18 & Brewer & -2.38 & 5.04 & 0.89 & 206 \\
Lindenberg & 52.21 & 14.12 & Brewer & -0.91 & 4.69 & 0.84 & 200 \\
Potsdam & 52.22 & 13.05 & Brewer & 0.48 & 4.32 & 0.79 & 21 \\
Potsdam & 52.22 & 13.05 & Dobson & 0.38 & 3.45 & 0.91 & 19 \\
Kaunas & 54.52 & 23.54 & Filter & -6.22 & 7.21 & 0.89 & 224 \\
Norrkoeping & 58.58 & 16.15 & Brewer & -2.59 & 6.02 & 0.87 & 261 \\
Lerwick & 60.13 & -1.18 & Dobson & -1.30 & 5.27 & 0.90 & 154 \\
Vindeln & 64.24 & 19.77 & Brewer & -2.90 & 5.50 & 0.90 & 240 \\
Fairbanks & 64.82 & -147.87 & Dobson & -1.58 & 4.38 & 0.92 & 65 \\
Barrow & 71.32 & -156.60 & Dobson & -3.20 & 4.45 & 0.97 & 42 \\
Poprad-Ganovce & 49.03 & 20.32 & Brewer & -0.48 & 3.94 & 0.91 & 227 \\
\hline & & & & & & &
\end{tabular}

5, 4429-4475, 2005

\section{Retrieval and \\ validation of \\ SCIAMACHY ozone columns}

H. J. Eskes et al.

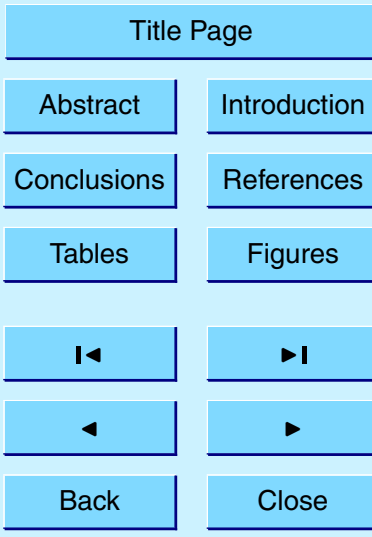

Full Screen / Esc

Print Version

Interactive Discussion 


\section{ACPD}

5, 4429-4475, 2005
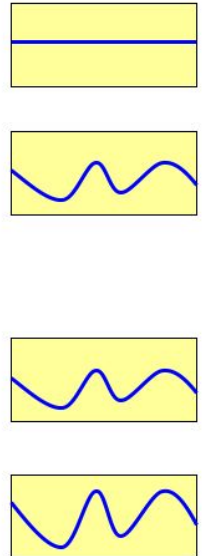

\section{Normalized Incident}

Sunlight

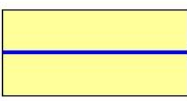

Ozone Absorption

Single Rayleigh Scattering

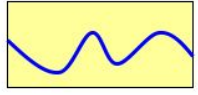

Cabannes

not scrambled

$96.2 \%$

Ozone

Absorption

Received by sensor
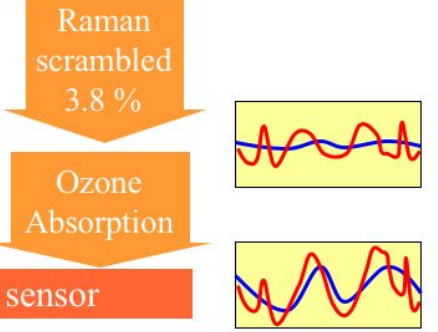

Fig. 1. Illustration of changes in the light intensity starting at the sun, crossing the atmosphere and moving to the satellite, for elastic (left part) and inelastic (right part) scattering. The blue lines represent the wavelength dependence of the ozone cross section, the red line represents the reflectance spectrum of inelastic scattered light.

\section{Retrieval and validation of SCIAMACHY ozone columns}

H. J. Eskes et al.

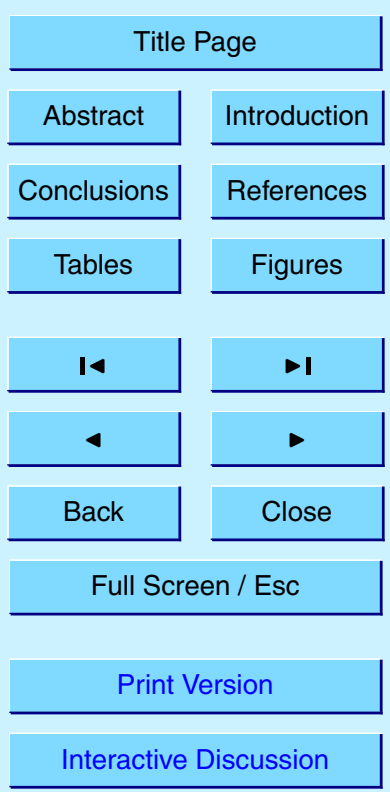




\section{ACPD}

$5,4429-4475,2005$

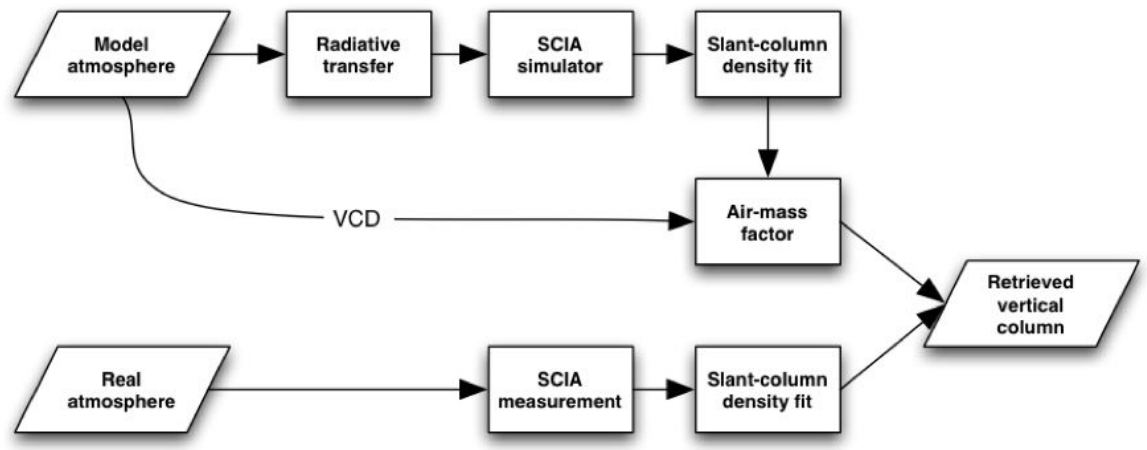

Fig. 2. Illustration of the empirical air-mass factor approach. High resolution spectra are generated with a radiative transfer model. A SCIAMACHY simulator converts this to spectra with the appropriate instrument resolution. Subsequently a DOAS fit is performed for the modelled spectrum and the air-mass factor is the ratio of the fitted slant column divided by the vertical column used in the radiative transfer calculation.

\section{Retrieval and validation of SCIAMACHY ozone columns}

H. J. Eskes et al.

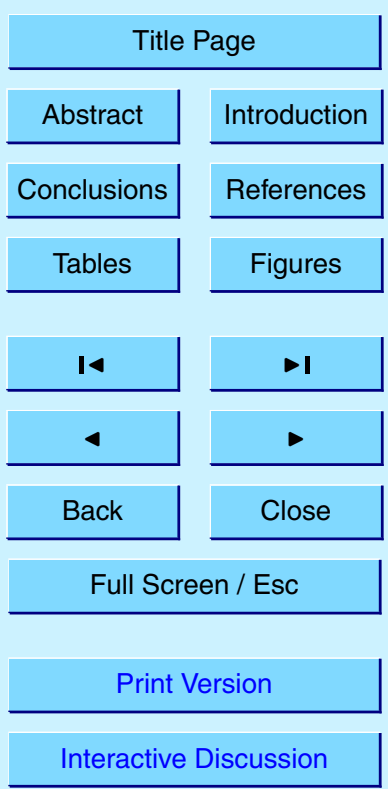




\section{ACPD}

$5,4429-4475,2005$

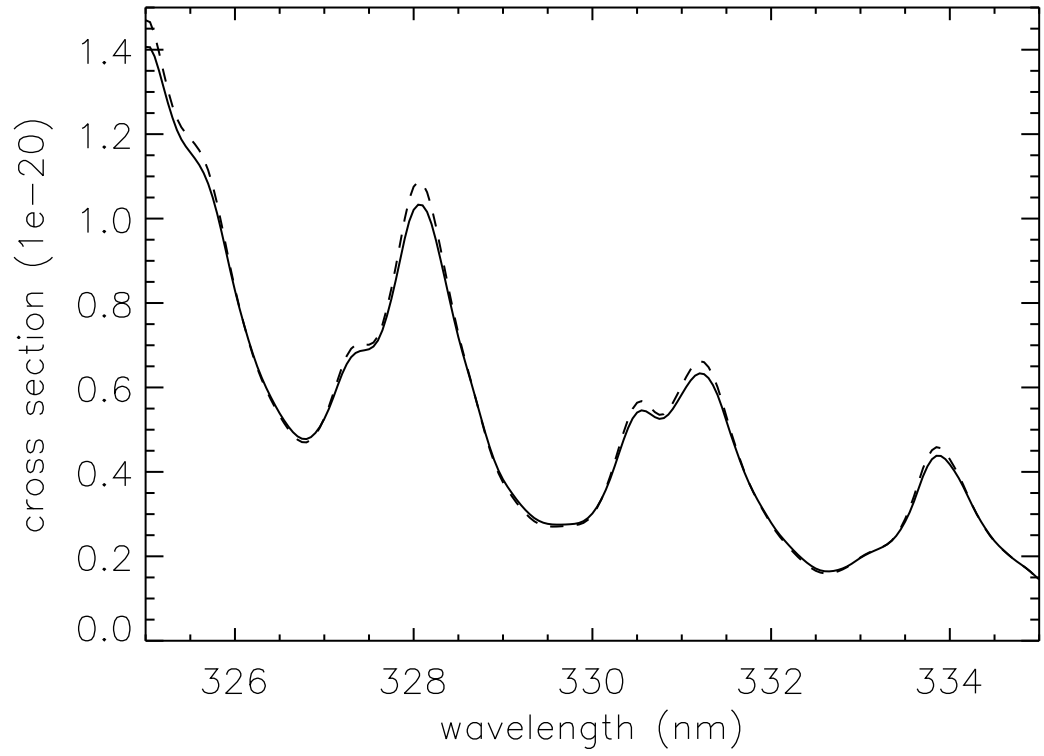

Retrieval and validation of SCIAMACHY ozone columns

H. J. Eskes et al.

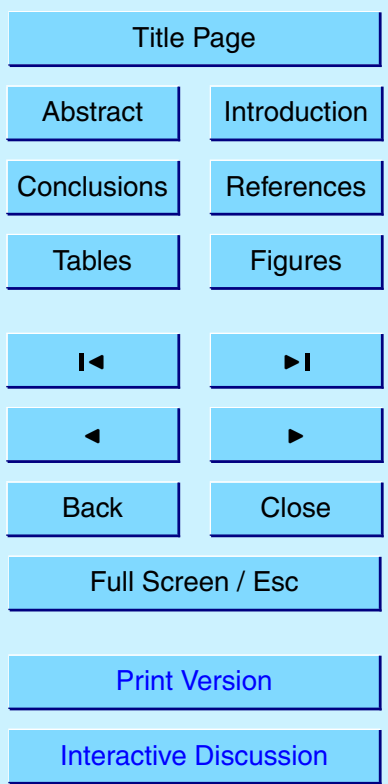

Fig. 3. A plot of the GOME Flight Model (dotted line) and SCIAMACHY Flight Model (solid line) cross sections for the $325-335 \mathrm{~nm}$ window. Both cross sections are broadened to the same spectral resolution as discussed in the text. 


\section{ACPD}

5, 4429-4475, 2005

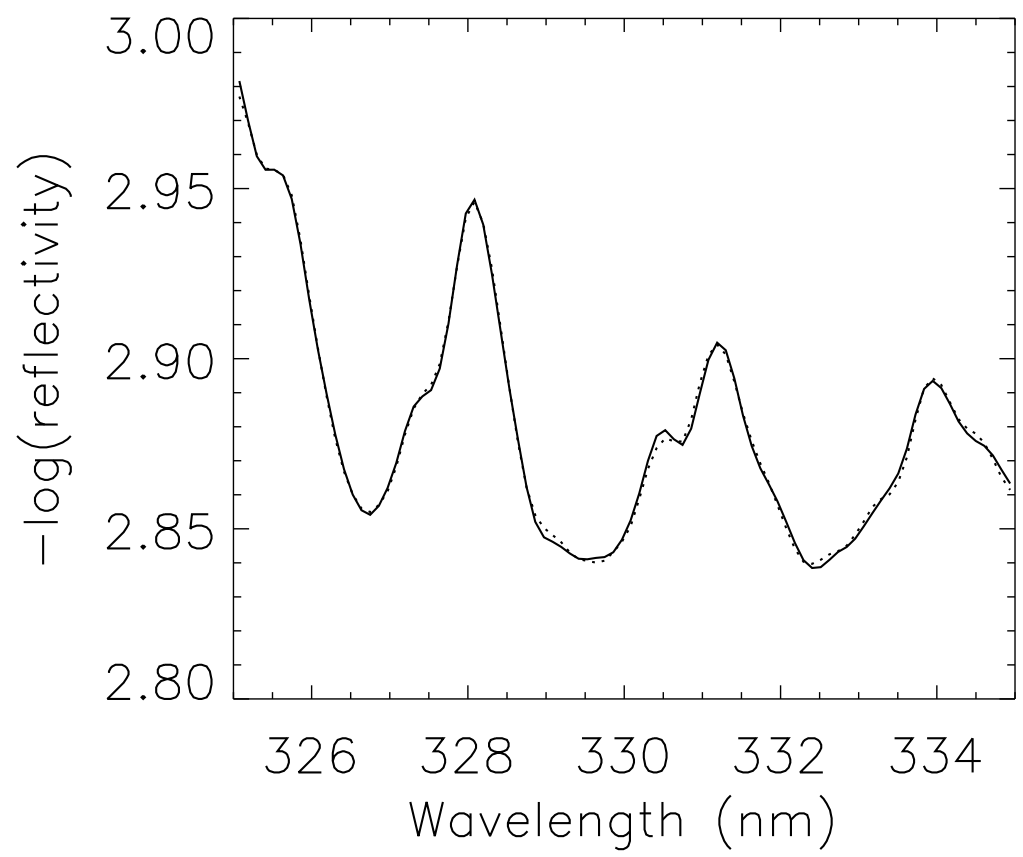

Retrieval and validation of SCIAMACHY ozone columns

H. J. Eskes et al.

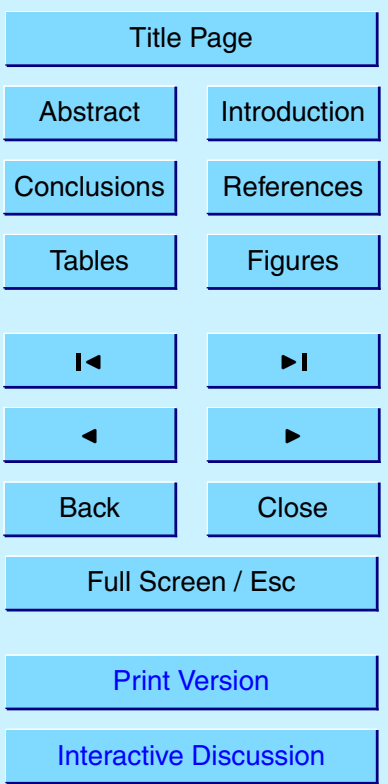




\section{ACPD}

$5,4429-4475,2005$

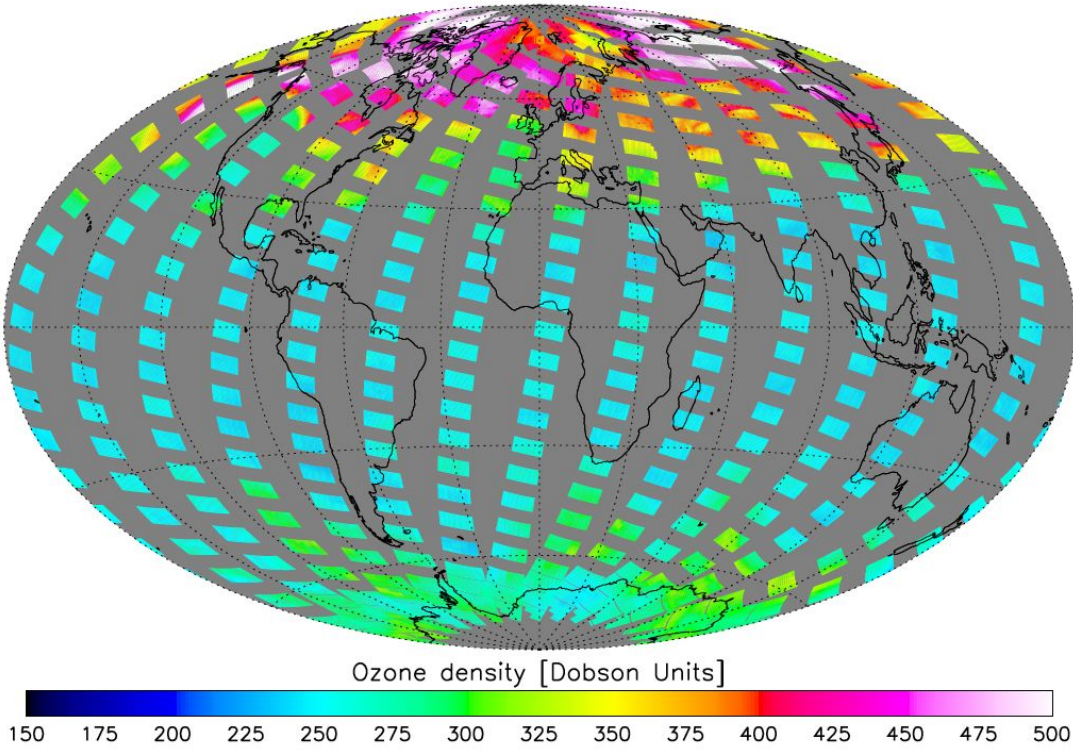

\section{Retrieval and} validation of SCIAMACHY ozone columns

H. J. Eskes et al.

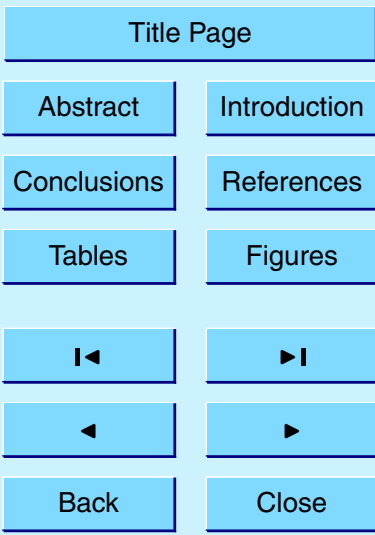

Fig. 5. TOSOMI total ozone retrievals for 20 March 2004.

Full Screen / Esc

Print Version

Interactive Discussion 


\section{ACPD}

$5,4429-4475,2005$

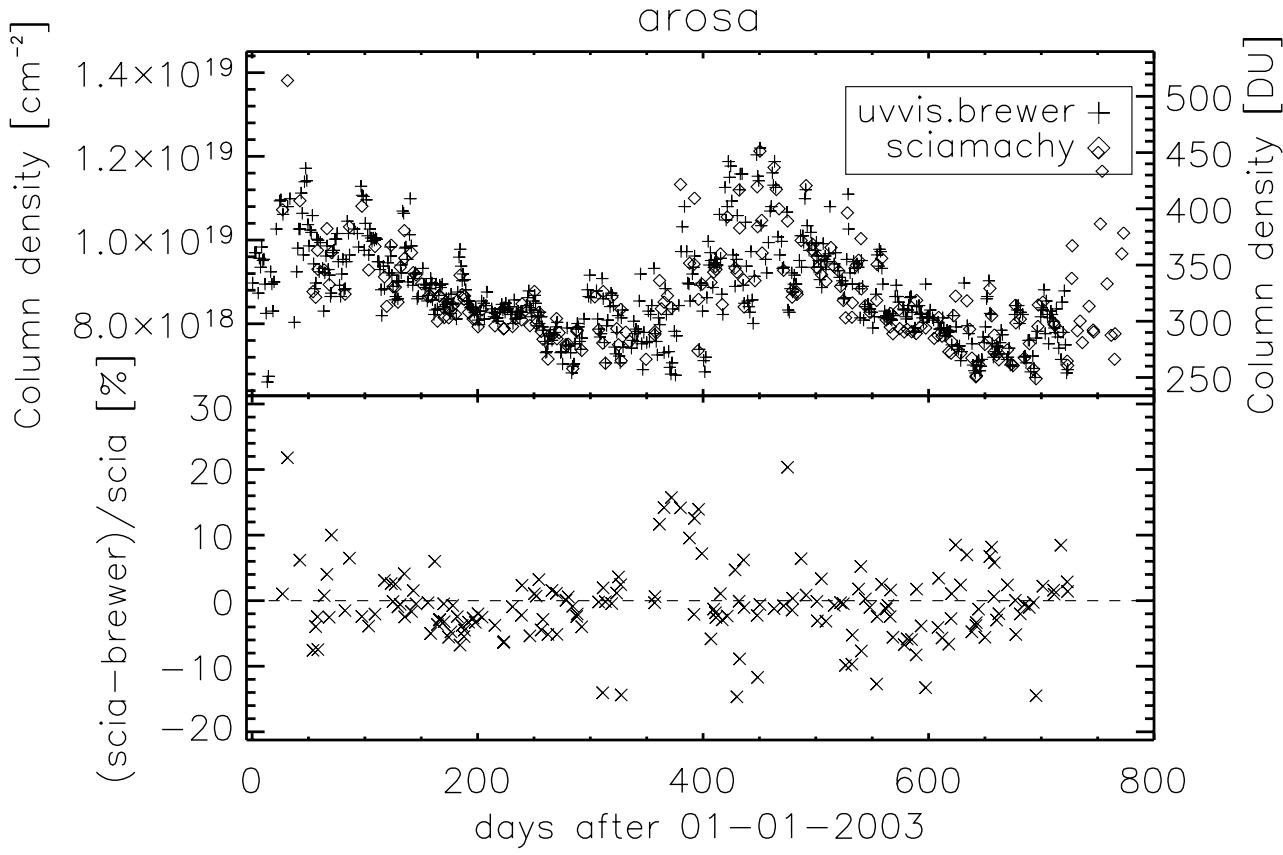

\section{Retrieval and validation of SCIAMACHY ozone columns}

H. J. Eskes et al.

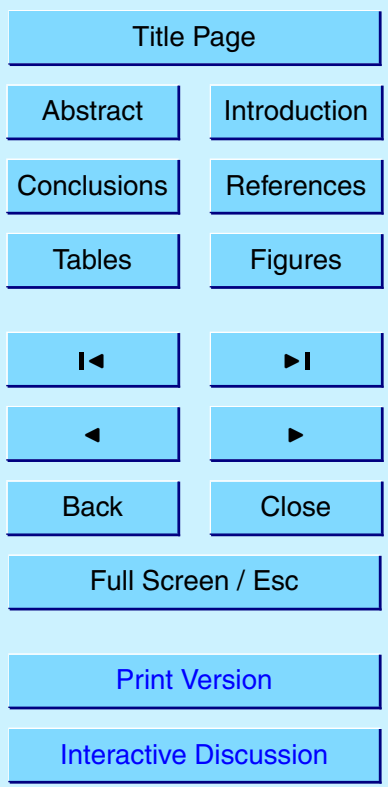

Fig. 6. Time series of Brewer ozone measurements at Arosa (46.78 N, 9.68 E), and collocated SCIAMACHY columns (top panel), and the relative difference between the two data sets. Relative differences are plotted for the closest matches of the satellite observations within a radius of $100 \mathrm{~km}$ and within $12 \mathrm{~h}$ time difference. 


\section{ACPD}

$5,4429-4475,2005$

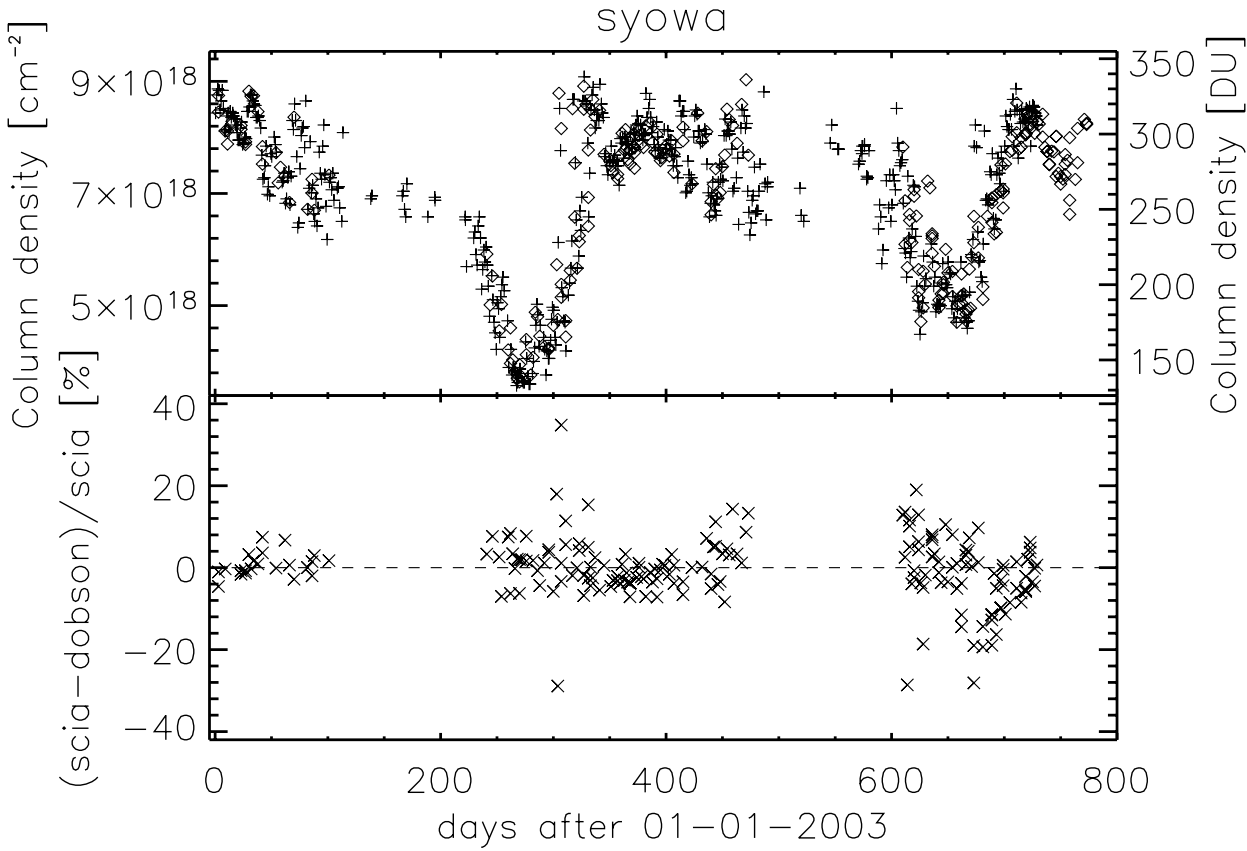

\section{Retrieval and validation of SCIAMACHY ozone columns}

H. J. Eskes et al.

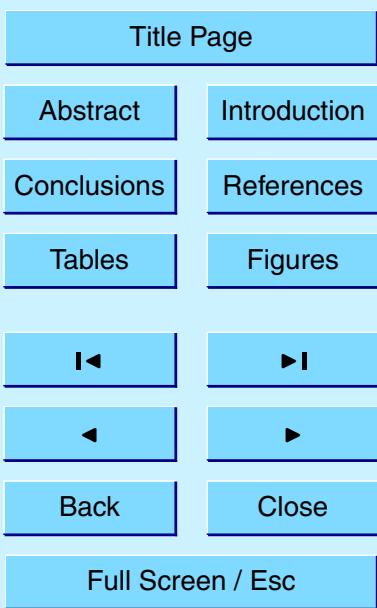

Fig. 7. Same as Fig. 6, but now for the Dobson instrument of Syowa station (69.00 S, 39.58 E).

Print Version

Interactive Discussion 


\section{ACPD}

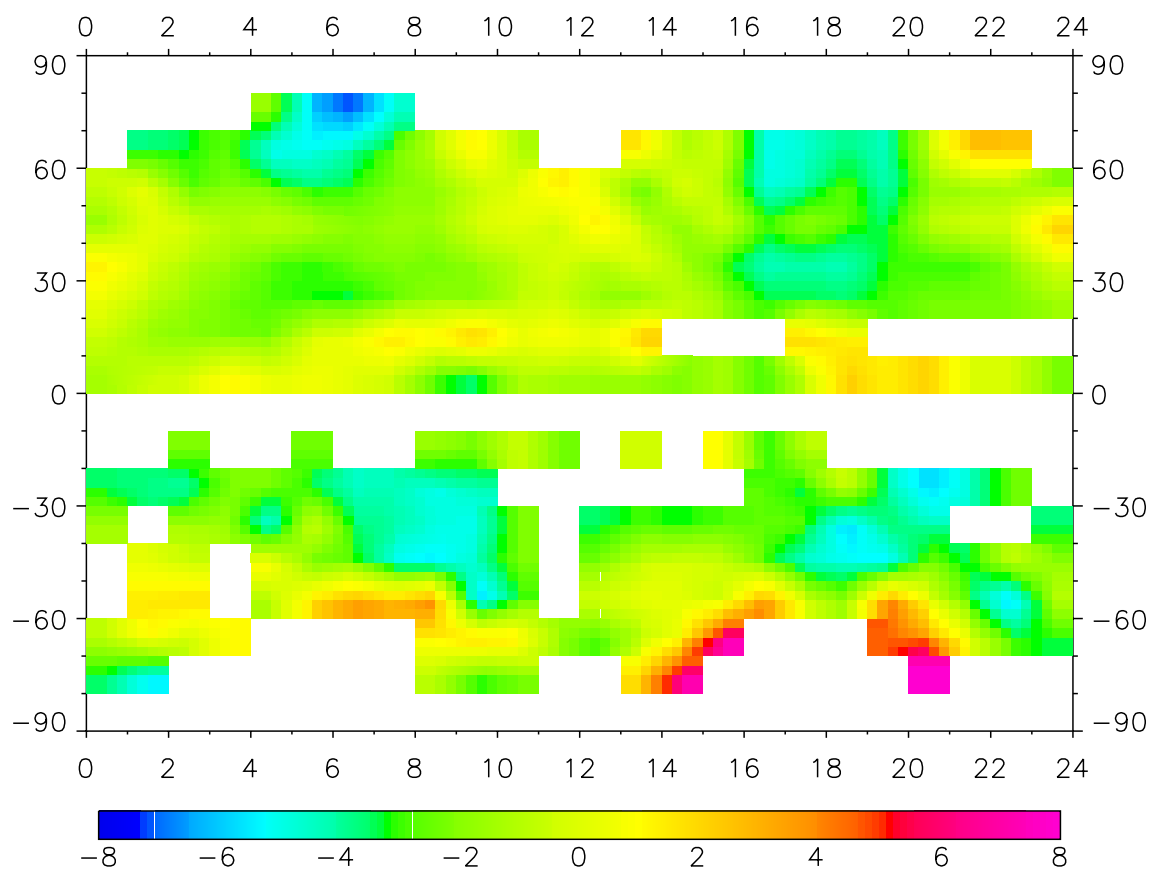

$5,4429-4475,2005$

\section{Retrieval and validation of SCIAMACHY ozone columns}

H. J. Eskes et al.

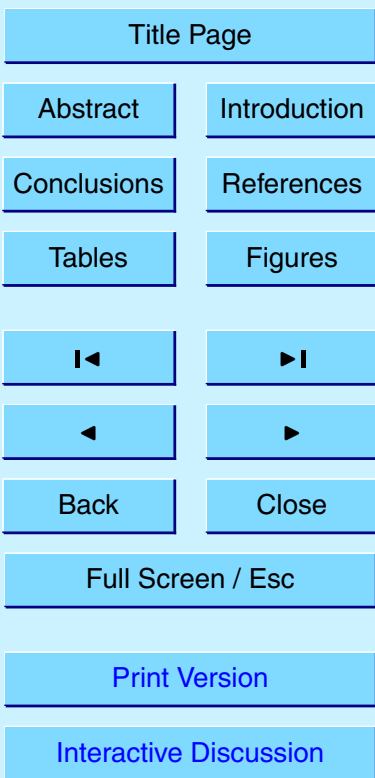

Fig. 8. Difference between TOSOMI columns and Brewer and Dobson stations in 2003 and 2004, as a function of the month since January 2003 (horizontal axis) and latitude (vertical axis). Colours show (TOSOMI-groundbased)/TOSOMI in percent. Data from 68 station is binned on 10 degree latitude and 1 month boxes. Data is only shown when more than 4 collocations occur within a box.

Interactive Discussion 


\section{ACPD}

$5,4429-4475,2005$

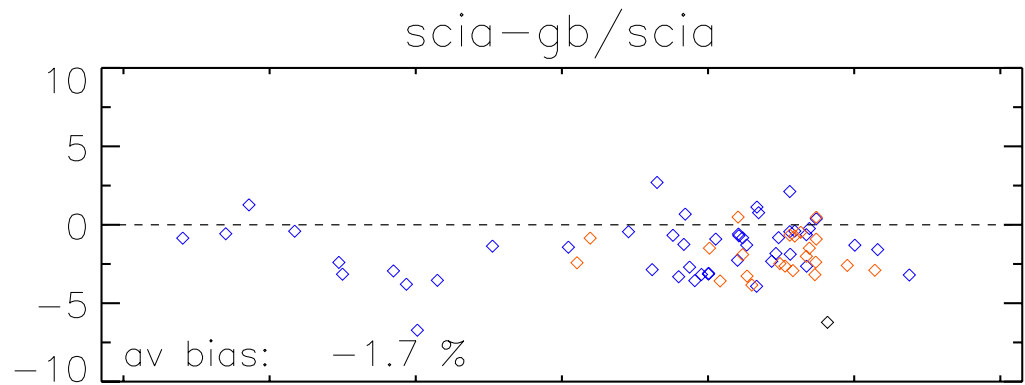

\section{Retrieval and validation of SCIAMACHY ozone columns}

H. J. Eskes et al.
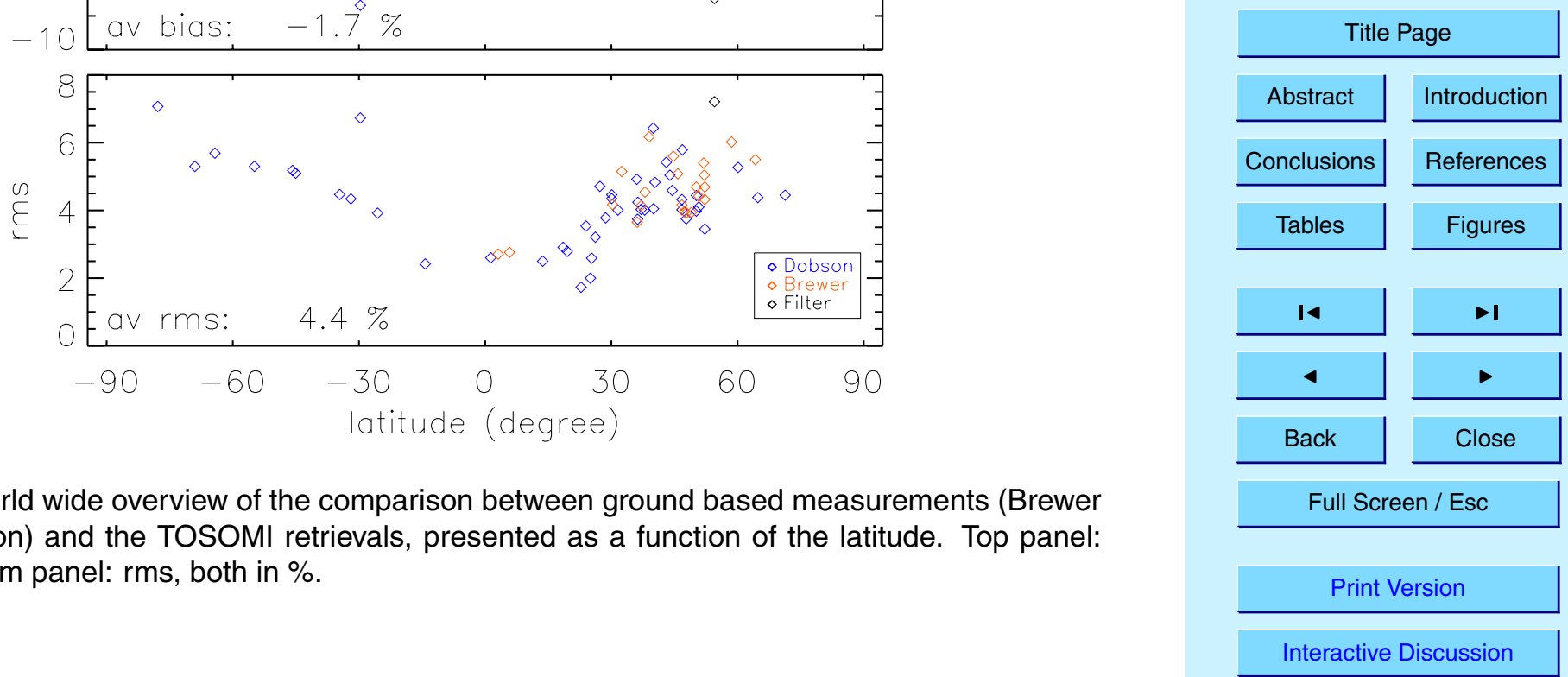

Fig. 9. World wide overview of the comparison between ground based measurements (Brewer and Dobson) and the TOSOMI retrievals, presented as a function of the latitude. Top panel: bias; bottom panel: rms, both in $\%$. 


\section{ACPD}

$5,4429-4475,2005$

\section{Biases ozone column data}

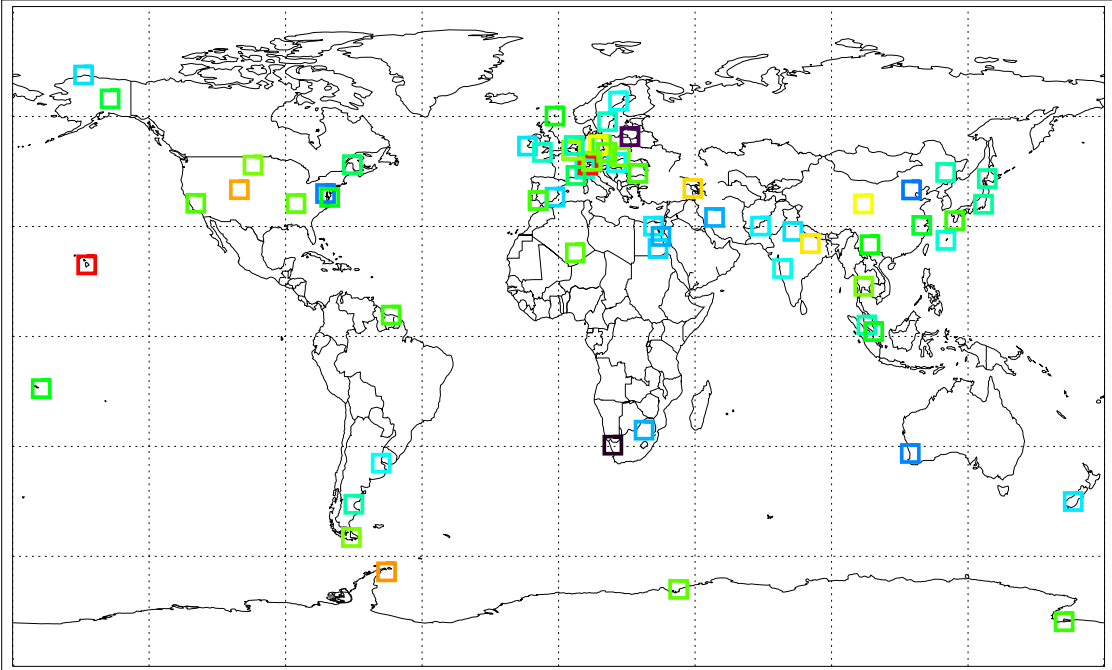

$$
(\mathrm{SC} \mid \mathrm{A}-\mathrm{gb}) / \mathrm{SCIA}[\%]
$$$$
\begin{array}{lllllllllll}
-7 & -6 & -5 & -4 & -3 & -2 & -1 & 0 & 1 & 2 & 3
\end{array}
$$

Fig. 10. A world map showing the locations of stations included in the comparison. The colours indicate the mean difference between SCIAMACHY and ground based ozone colums.

\section{Retrieval and validation of SCIAMACHY ozone columns}

H. J. Eskes et al.

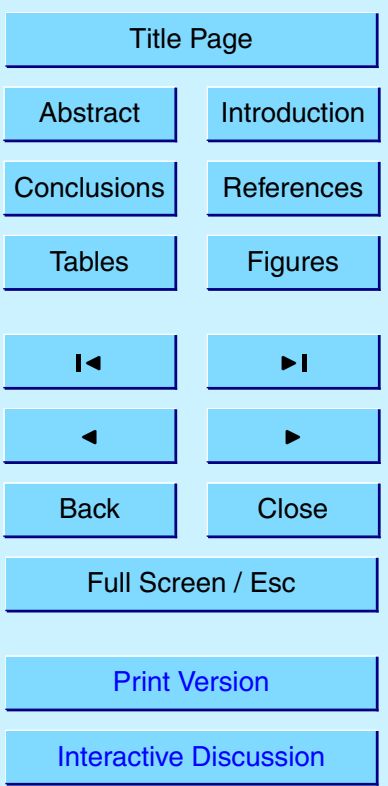




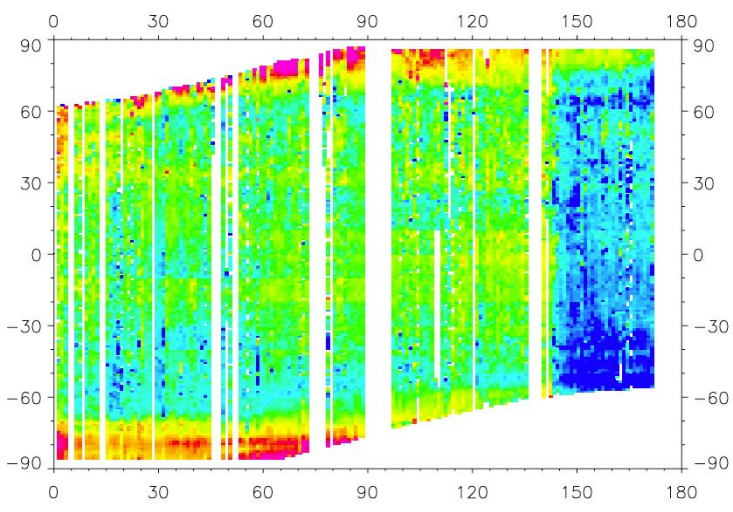

ACPD

$5,4429-4475,2005$

\section{Retrieval and validation of SCIAMACHY ozone columns}

H. J. Eskes et al.
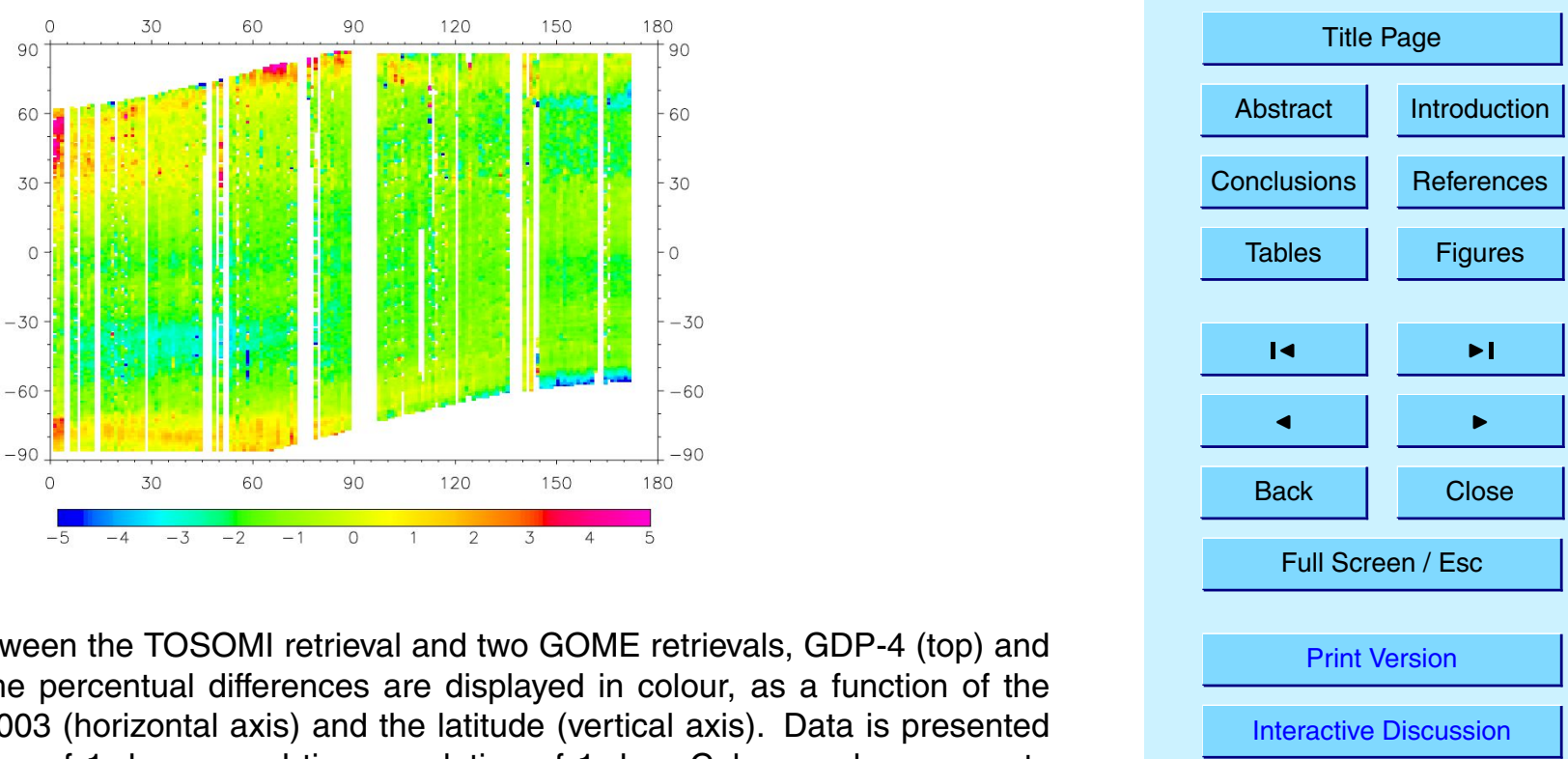

Fig. 11. Difference between the TOSOMI retrieval and two GOME retrievals, GDP-4 (top) and TOGOMI (bottom). The percentual differences are displayed in colour, as a function of the day since 1 January 2003 (horizontal axis) and the latitude (vertical axis). Data is presented with a latitude resolution of 1 degree and time resolution of 1 day. Colour scale represents (TOSOMI-GOME)/GOME in \%. 


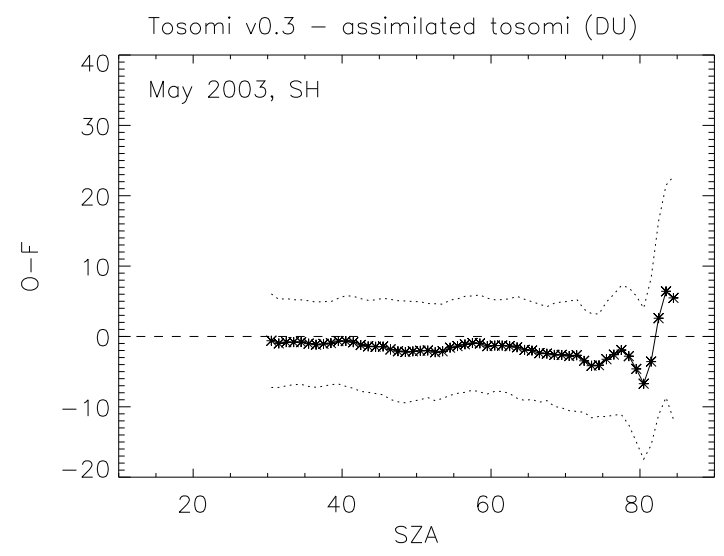

\section{ACPD}

$5,4429-4475,2005$

\section{Retrieval and validation of SCIAMACHY ozone columns}

H. J. Eskes et al.
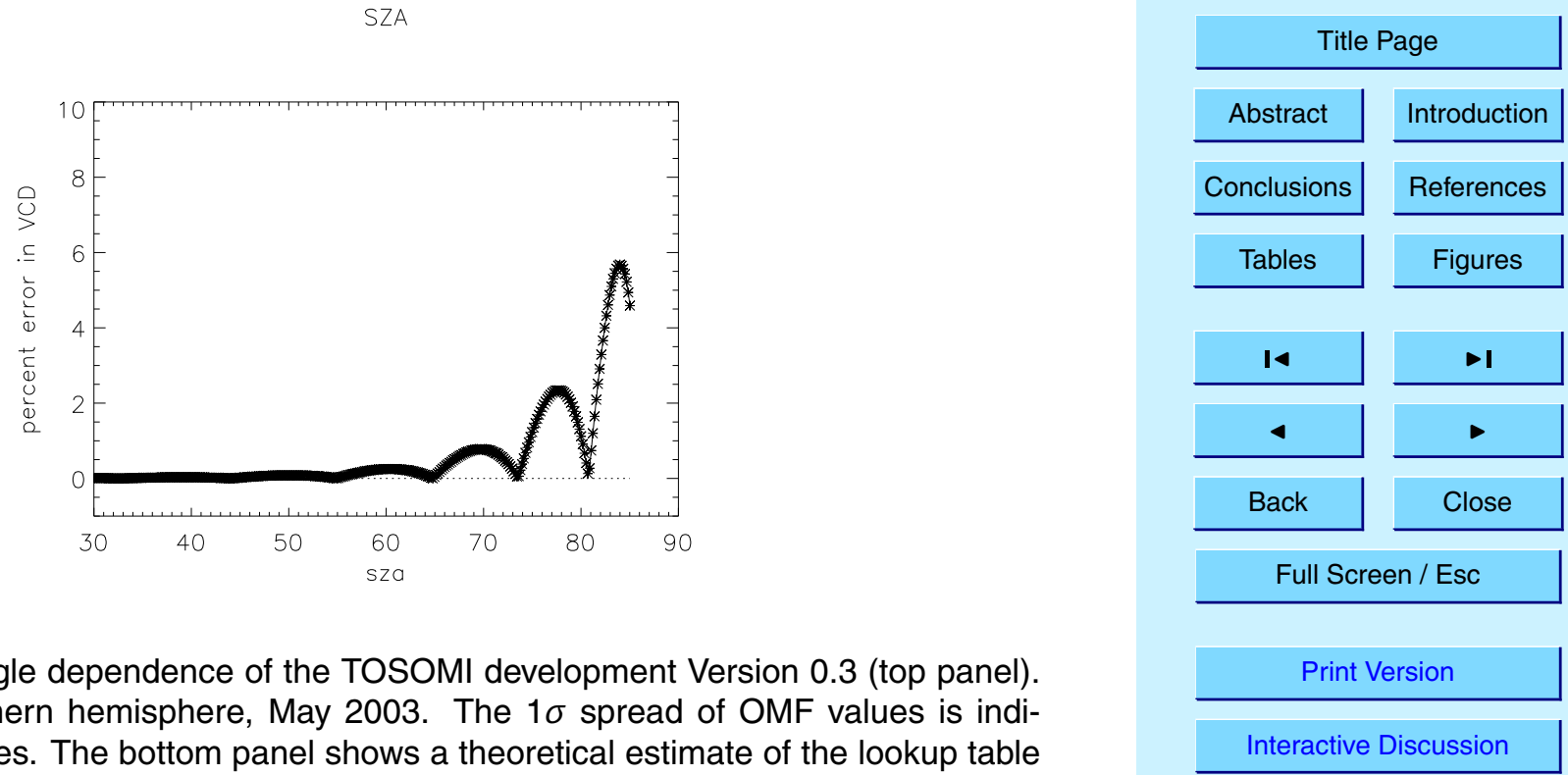

Fig. 12. Solar zenith angle dependence of the TOSOMI development Version 0.3 (top panel). The plot is for the southern hemisphere, May 2003. The $1 \sigma$ spread of OMF values is indicated by the dotted curves. The bottom panel shows a theoretical estimate of the lookup table interpolation error described in the text. 


\section{ACPD}

$5,4429-4475,2005$

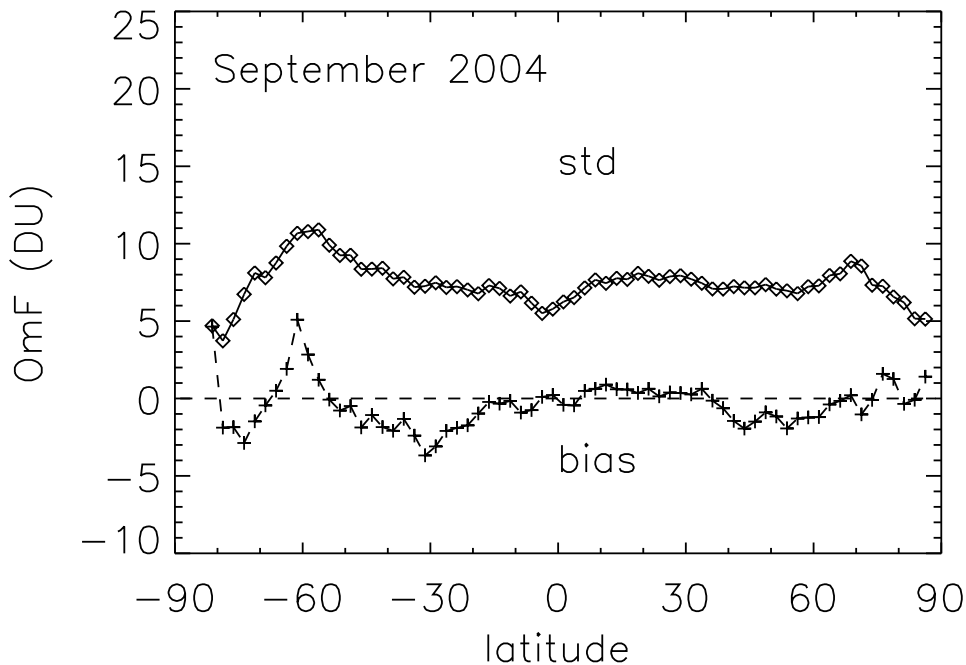

\section{SCIAMACHY ozone} columns

H. J. Eskes et al.

Fig. 13. Observation minus forecast differences as a function of latitude, averaged for the month September 2004. The plot shows the mean bias (solid) and standard deviation.

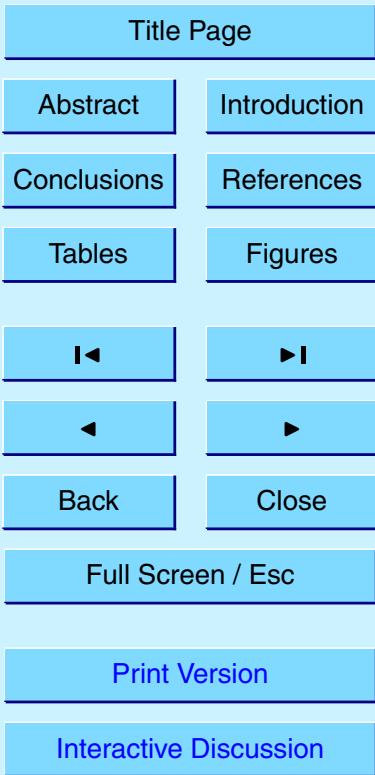




\section{ACPD}

$5,4429-4475,2005$

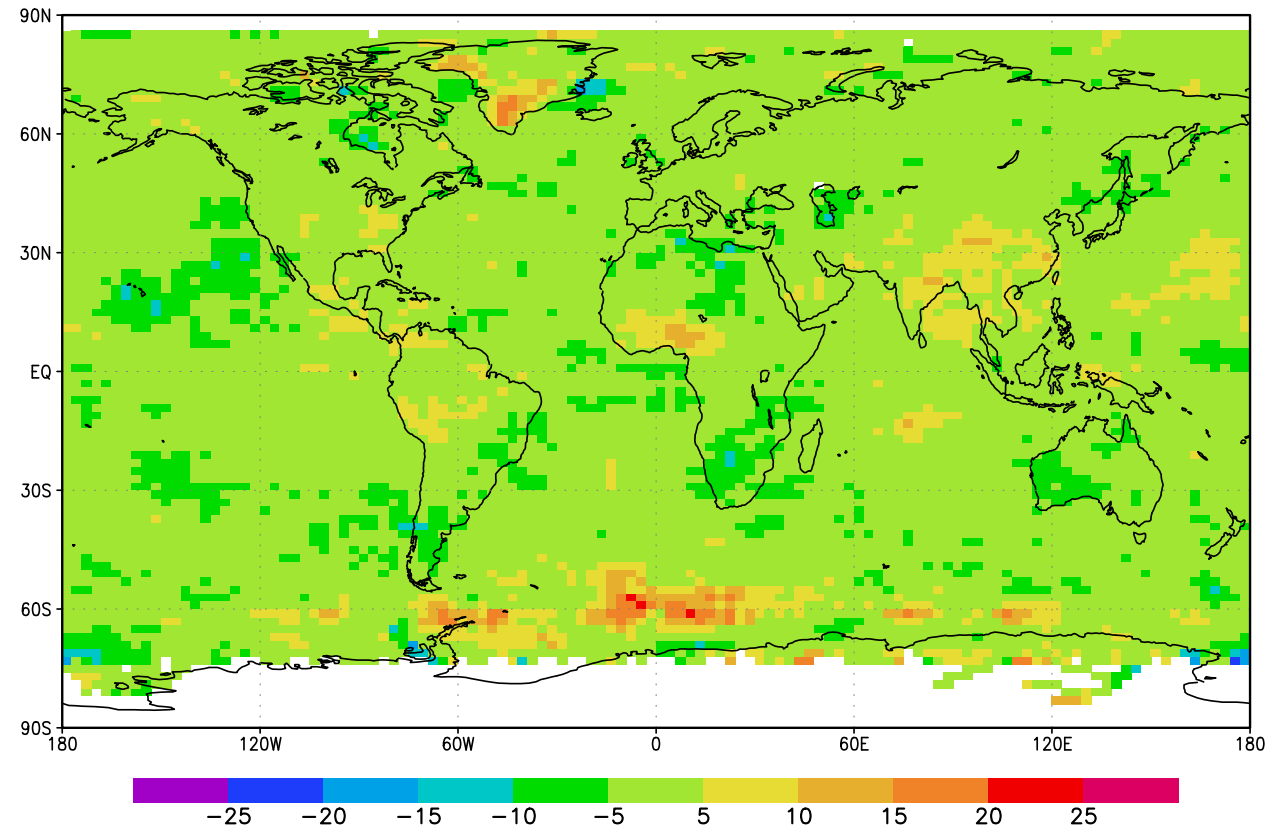

validation of

SCIAMACHY ozone columns

H. J. Eskes et al.

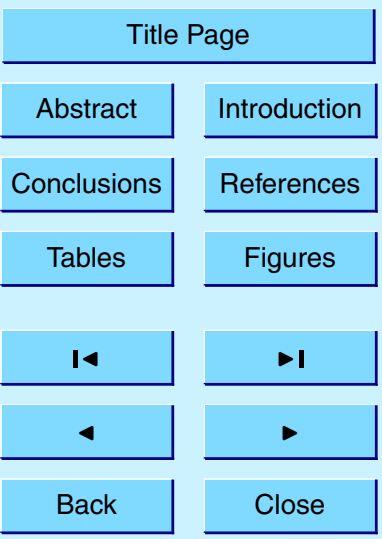

Full Screen / Esc

Fig. 14. Observation minus forecast differences for September 2004. Scale in Dobson Units.

Print Version

Interactive Discussion 


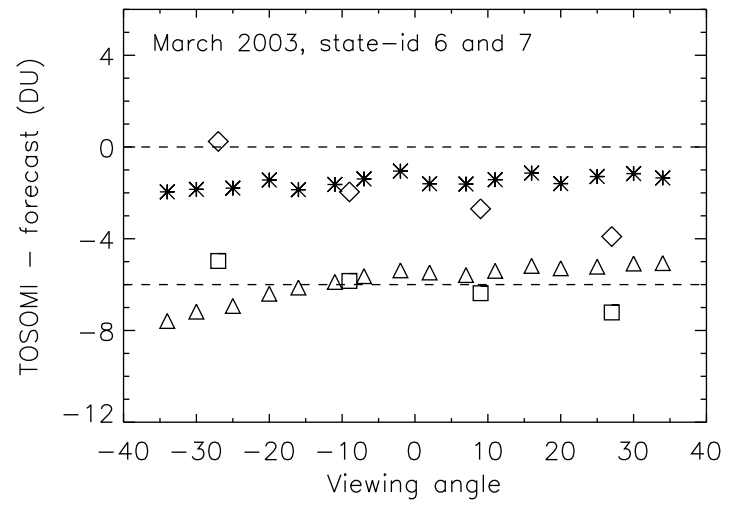

\section{ACPD}

$5,4429-4475,2005$

\section{Retrieval and validation of SCIAMACHY ozone columns}

H. J. Eskes et al.
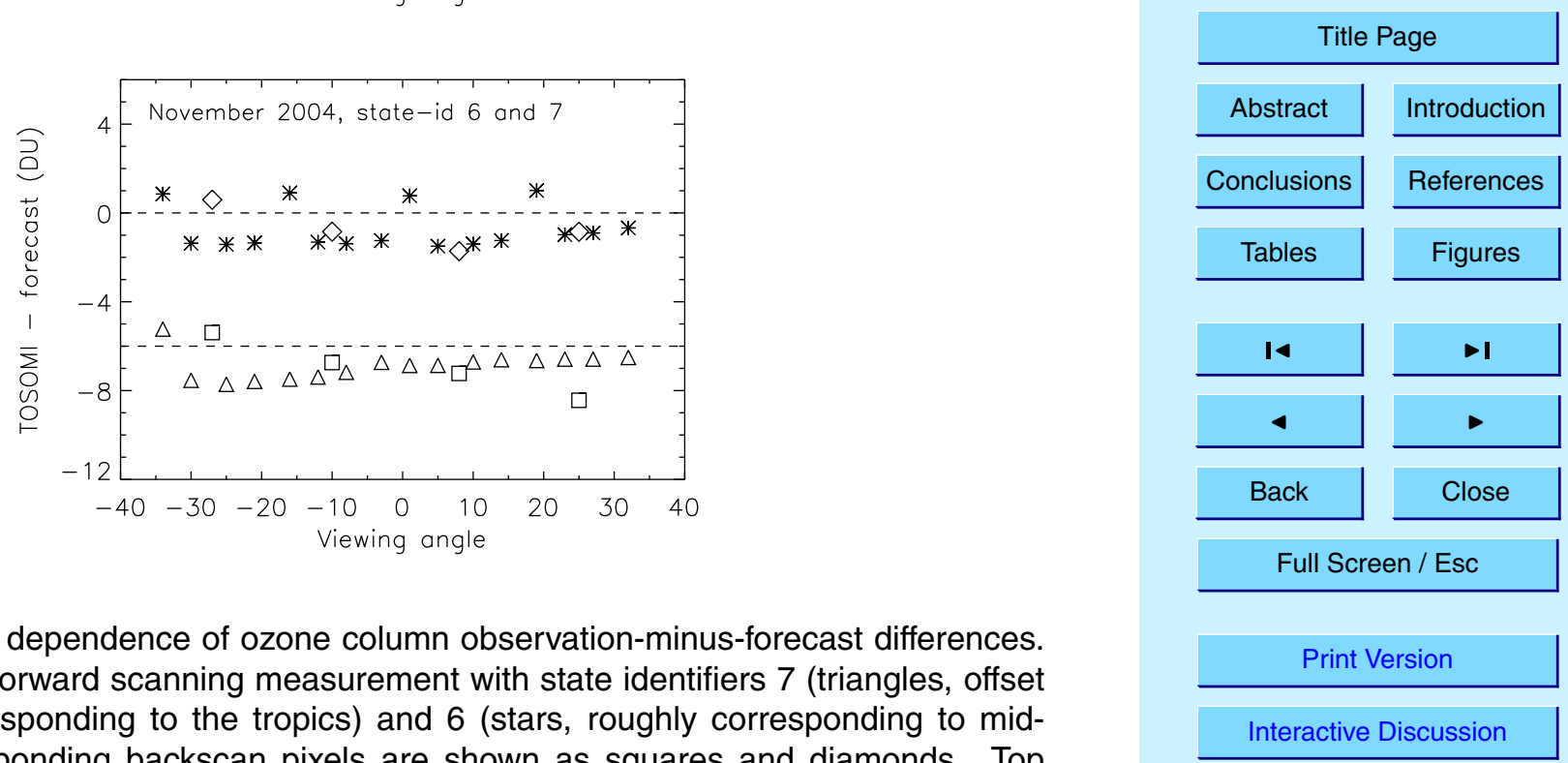

Fig. 15. Viewing angle dependence of ozone column observation-minus-forecast differences. Results are shown for forward scanning measurement with state identifiers 7 (triangles, offset by $6 \mathrm{DU}$, roughly corresponding to the tropics) and 6 (stars, roughly corresponding to midlatitudes). The corresponding backscan pixels are shown as squares and diamonds. Top Interactive Discussion panel: March 2003, Bottom panel: November 2004. 


\section{ACPD}

$5,4429-4475,2005$

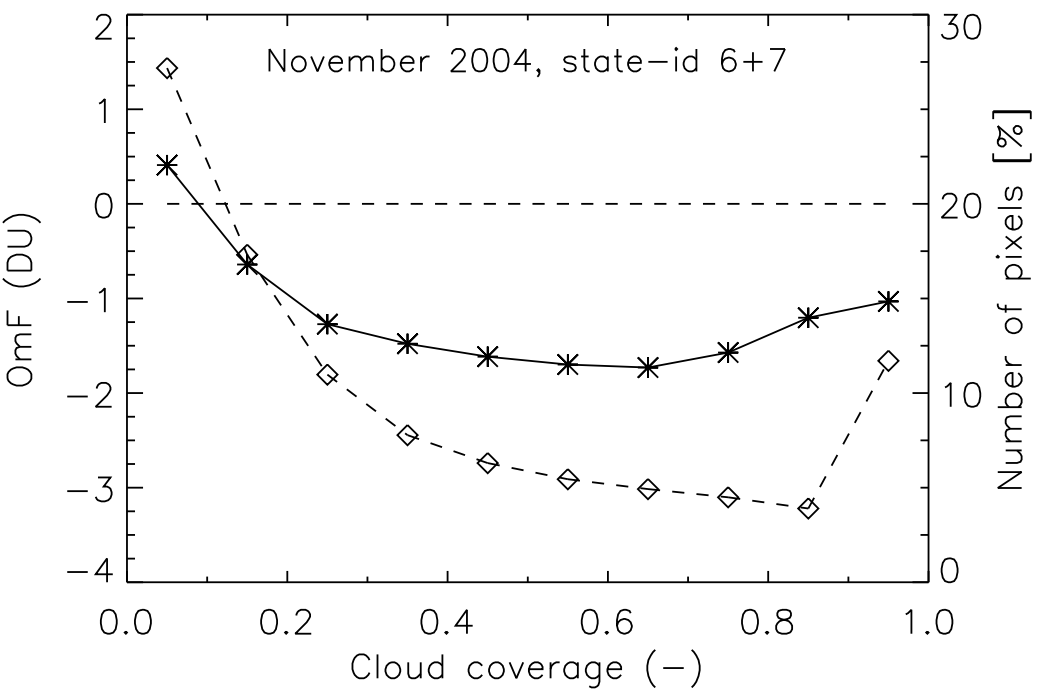

Fig. 16. Cloud fraction dependence of ozone column observation-minus-forecast differences (solid line, scale on the left, in Dobson units), and the fraction of pixels with a given cloud fraction (dotted line, scale on the right), for November 2004 and for retrievals with state identifiers 6 and 7.

\section{Retrieval and validation of SCIAMACHY ozone columns}

H. J. Eskes et al.

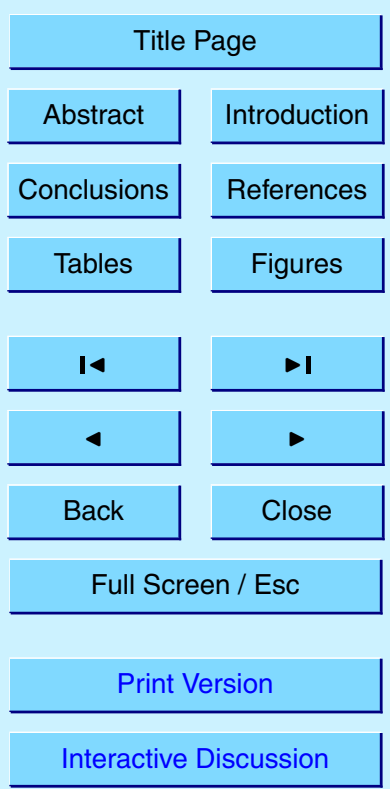

